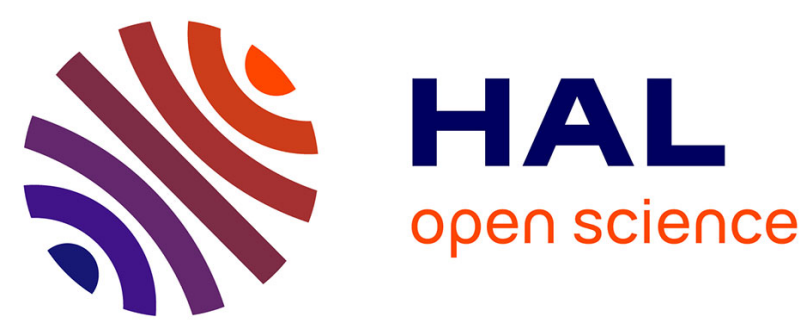

\title{
Temperature distribution in a permafrost-affected rock ridge from conductivity and induced polarization tomography
}

P-A Duvillard, F Magnin, A Revil, A Legay, Ludovic Ravanel, F Abdulsamad, A Coperey

\section{To cite this version:}

P-A Duvillard, F Magnin, A Revil, A Legay, Ludovic Ravanel, et al.. Temperature distribution in a permafrost-affected rock ridge from conductivity and induced polarization tomography. Geophysical Journal International, 2020, 225, pp.1207 - 1221. 10.1093/gji/ggaa597 . hal-03226968

\section{HAL Id: hal-03226968 \\ https://hal.science/hal-03226968}

Submitted on 16 May 2021

HAL is a multi-disciplinary open access archive for the deposit and dissemination of scientific research documents, whether they are published or not. The documents may come from teaching and research institutions in France or abroad, or from public or private research centers.
L'archive ouverte pluridisciplinaire HAL, est destinée au dépôt et à la diffusion de documents scientifiques de niveau recherche, publiés ou non, émanant des établissements d'enseignement et de recherche français ou étrangers, des laboratoires publics ou privés. 


\title{
Temperature distribution in a permafrost-affected rock ridge from conductivity and induced polarization tomography
}

\author{
P.-A. Duvillard, ${ }^{1,2}$ F. Magnin, ${ }^{1}$ A. Revil, ${ }^{1}$ A. Legay, ${ }^{1}$ L. Ravanel, ${ }^{1}$ F. Abdulsamad ${ }^{1}$ and \\ A. Coperey ${ }^{1}$ \\ ${ }^{1}$ EDYTEM, Université Savoie Mont-Blanc, CNRS, 73000 Chambery, France.E-mail: andre.revil@univ-smb.fr \\ ${ }^{2}$ PACTE, Université Grenoble Alpes, CNRS, 38000 Grenoble, France
}

Accepted 2020 December 15. Received 2020 December 12; in original form 2020 April 4

\begin{abstract}
S UMMAR Y
Knowledge of the thermal state of steep alpine rock faces is crucial to assess potential geohazards associated with the degradation of permafrost. Temperature measurements at the rock surface or in boreholes are however expensive, invasive, and provide spatially limited information. Electrical conductivity and induced polarization tomography can detect permafrost. We test here a recently developed petrophysical model based on the use of an exponential freezing curve applied to both electrical conductivity and normalized chargeability to infer the distribution of temperature below the freezing temperature. We then apply this approach to obtain the temperature distribution from electrical conductivity and normalized chargeability field data obtained across a profile extending from the SE to NW faces of the lower Cosmiques ridge (Mont Blanc massif, Western European Alps, 3613 m a.s.l., France). The geophysical data sets were acquired both in 2016 and 2019. The results indicate that only the NW face of the rock ridge is frozen. To evaluate our results, we model the bedrock temperature across this rock ridge using CryoGRID2, a 1-D MATLAB diffusive transient thermal model and surface temperature time-series. The modelled temperature profile confirms the presence of permafrost in a way that is consistent with that obtained from the geophysical data. Our study offers a promising low-cost approach to monitor temperature distribution in Alpine rock walls and ridges in response to climate change.
\end{abstract}

Key words: Electrical properties; Hydrogeophysics; Electrical resistivity tomography (ERT).

\section{INTRODUCTION}

According to IPA (International Permafrost Association), permafrost is defined as 'ground (soil or rock and included ice or organic material) that remains at or below $0{ }^{\circ} \mathrm{C}$ for at least two consecutive years' (Dobinski 2011). Permafrost in mid-latitude mountain areas is currently strongly affected by climate change (e.g. Biskaborn et al. 2019; PERMOS 2019). In turn, permafrost degradation (warming and thawing of the ice content) is known to have serious consequences on the mechanical properties of the rock slopes (Gruber \& Haeberli 2007; Krautblatter et al. 2013), resulting in an increasing rockfall frequency and magnitude that affects high mountain rock walls (Haeberli \& Beniston 1998; Ravanel \& Deline 2011; Ravanel et al. 2017). A precise knowledge of the thermal state of permafrost in rock walls and rock ridges is therefore crucial for assessing the safety and reliability of mountain infrastructures (Haeberli et al. 2010; Krautblatter et al. 2012), and to prevent or limit their damages or disturbances (Duvillard et al. 2019).
Rock wall temperature can be directly determined and monitored by the means of temperature sensors installed at the rock surface or in boreholes (e.g. Magnin et al. 2015a). Since these data are local (point or line measurements), they are commonly used to fit statistical models explaining the rock surface temperature (RST, e.g. Boeckli et al. 2012). They can be also used to parameterize or validate physics-based models (i.e. based on solving the heat equation) to infer the spatial distribution and evolution of rock wall permafrost and temperature when direct measurements are missing (e.g. Gruber et al. 2004; Magnin et al. 2017a; Magnin et al. 2019). However, the accuracy of the models is limited because of (i) a lack of consideration of important parameters driving the energy balance at the rock surface (e.g. variability in solar radiation or snow deposit), (ii) the rock material characteristics (e.g. the thermal conductivity, porosity, specific heat storage coefficient) are generally defined upon standard values, considered as homogenous and isotropic, and finally because (iii) complex heat transfer processes such as heat advection in bedrock fractures resulting from air circulation or water infiltration are neglected. That said, simplified 
thermal models have been shown to be reliable to estimate the permafrost characteristics at a given time period at depth $>8 \mathrm{~m}$, and to estimate its changes over pluriannual timescales (Magnin et al. 2017).

To overcome some of the limits of direct temperature measurements and numerical modelling, electrical conductivity and induced polarization tomography can provide an alternative and complementary way to estimate the extent of permafrost and temperature distribution below the freezing temperature. In the past, electrical conductivity tomography has been broadly used to detect and monitor mountain permafrost (e.g. Hauck 2002; Hauck et al. 2003; Kneisel 2006; Krautblatter \& Hauck 2007; Fortier et al. 2008; Hauck et al. 2011; Supper et al. 2014; Mollaret et al. 2019) including in steep rock walls (Magnin et al. 2015b; Keuschnig et al. 2017). Indeed, the electrical conductivity of frozen rocks is much lower with respect to unfrozen materials (see, for instance, Scott et al. 1990; Maurer \& Hauck 2007; Kneisel et al. 2008). The advantages of these geophysical methods are their low cost, their non-invasive character, and the fact that they provide 2-D or 3-D tomograms/images of the subsurface. That being said, electrical resistivity tomography (ERT) yields only qualitative information on the thermal state of materials because electrical conductivity depends on many parameters including water content, salinity, cation exchange capacity, and temperature. In addition, it is not sure that neglecting the effect of surface conduction (occurring at the liquid water/ice or solid interface) in the expression of the effective electrical conductivity of the mixture is a correct assumption. This assumption is however widely used in the literature without any critical analysis or corroboration through petrophysical investigations. For instance, Hauck et al. (2011) developed a model that combines ERT and seismic $P$-wave velocity and uses the parameters in the classical Archie's (1942) law and an extended Timur's (1968) equation to gain insight into the porosity distribution. Petrophysical joint inversion honoring both data sets and petrophysical relations during parameter estimation have been developed and tested for porous sites in Switezerland (Wagner et al. 2019, Mollaret et al. 2020).

Magnin et al. (2015b) used laboratory experiments to distinguish frozen from unfrozen rocks based on their electrical conductivity. Krautblatter et al. (2010) documented relative changes in resistivity during a period of about half a year and gave temperature changes associated with these resistivity changes. Currently, there is however a marked absence of a rigorous protocol to infer the temperature distribution from electrical conductivity tomography including the effect of surface conduction and the salt segregation in the liquid water phase. Abusing Archie's law without accounting for the salt segregation (see discussion in Duvillard et al. 2018; Herring et al. 2019) has been generally the rule with few exceptions. To our knowledge, these limitations are due to the lack of a precise petrophysical-based methodology to infer temperature fields from electrical conductivity tomograms. The conversion of electrical conductivity into temperature distribution has however been successfully accomplished for other geological contexts than permafrost such as, for instance, active volcanoes (Revil et al. 2018) or around heat exchangers (Coperey et al. 2019b). A similar strategy is followed in the present work following the recent developments in Duvillard et al. (2018) and Coperey et al. (2019a,b).

In addition to electrical conductivity tomography, another geophysical method called induced polarization is sometimes used to infer the presence of permafrost (e.g. Doetsch et al. 2015, Grimm \& Stillman 2015, Duvillard et al. 2018; Abdulsamad et al. 2019;
Mudler et al. 2019). Induced polarization refers to the reversible storage of electrical charges in a porous material under a lowfrequency varying (applied) electrical field (e.g. Seigel 1959; Kemna et al. 2012; Weller et al. 2013). In absence of metallic particles and in presence of moisture in a porous or fractured rock, induced polarization is related to the properties of the electrical double layer coating the surface of the grains (Revil 2012, 2013; Leroy et al. 2017). Recently, the dynamic Stern layer concepts developed by Revil $(2012,2013)$ have been extended to freezing conditions (Duvillard et al. 2018; Abdulsamad et al. 2019; Revil et al. 2019a; Coperey et al. 2019b). One of the advantages of induced polarization is that it can be measured with the same equipment as that used for electrical conductivity data acquisition (e.g. Kemna et al. 2012).

The recent establishment of a unified petrophysical model describing both electrical conductivity and induced polarization (normalized chargeability) of rocks in freezing conditions provides the opportunity to convert electrical conductivity to temperature in areas affected by permafrost. Our study proposes to investigate the potential of these geophysical measurements and petrophysical models tested on rock samples from outcrops to assess the temperature field patterns of a high-Alpine rock ridge. We apply our approach to electrical conductivity and induced polarization data measured across the permafrost-affected lower Cosmiques ridge (3613 $\mathrm{m}$ a.s.1.), in the Mont Blanc massif (Western European Alps, France), below a refuge damaged by a $600-\mathrm{m}^{3}$ rockfall in 1998 August (Ravanel et al. 2013). To evaluate the results from the geophysical data, we use the RST time-series collected on each side of the ridge (from 2016 July to 2019 September on the north face and from 2016 July to 2020 April on the south face) to force a nonlinear 1-D heat conduction model simulating the temperature across a profile crossing the ridge. This modelling exercise is performed to see if the frozen portion of the ridge is consistent with the temperature prediction from the geophysical and petrophysical data.

\section{PETROPHYSICS}

\subsection{Electrical conductivity-temperature relationship}

Above the freezing temperature, the change in the electrical conductivity of a rock with temperature is controlled by the temperature dependence of the ionic mobilities, which is in turn controlled by the temperature dependence of the dynamic viscosity of the pore water. In these conditions, the temperature dependence of the electrical conductivity $\sigma(T)$ at temperature $T$ (in $\mathrm{S} \mathrm{m}^{-1}$ ) is given by Revil et al. (2018):

$\sigma(T)=\sigma\left(T_{0}\right)\left[1+\alpha_{T}\left(T-T_{0}\right)\right]$,

where $\alpha_{T}=0.021^{\circ} \mathrm{C}^{-1}$ (i.e. the temperature dependence of the conductivity is roughly 2 per cent per degree Celsius, independent of the water content of the rock), the reference temperature is $T_{0}=25^{\circ} \mathrm{C}$, and $\sigma\left(T_{0}\right)$ denotes the conductivity of the rock at the reference temperature. The conductivity of a rock represents the ability of the rock to conduct an electrical current under the application of an electrical field. It comprises two contributions: a bulk contribution associated with conduction in the bulk pore space and a surface conductivity associated with conduction in the electrical double layer coating the surface of the grains. Usually, in a shallow temperature field above freezing conditions, the spatial variability associated with the effect of temperature ( 2 per cent change per degree Celsius) is much smaller than 
the variability associated with the variations in spatial magnitude of the porosity, texture and surface conductivity. It follows that above the freezing temperature, a single snapshot of the electrical conductivity distribution cannot be used to infer the temperature distribution.

In freezing conditions, part of the liquid pore water of a rock is progressively transformed into ice so there is also an additional effect associated with the change of the water content itself. Since the salt remains segregated in the liquid pore water, the salinity of the liquid pore water increases with the decrease of temperature. These effects imply a strong impact of the temperature on the electrical conductivity, an impact that is much stronger than above the freezing temperature. To quantitatively assess these effects, few ingredients are however required. The most important is the expression of a freezing curve describing the relationship, for a given porous material, between the liquid water content $\theta$ (dimensionless) and the temperature $T$ (in ${ }^{\circ} \mathrm{C}$ ). In Duvillard et al. (2018) and Coperey et al. (2019b), the following exponential freezing curve was proposed and validated:

$\theta(T)=\left\{\begin{array}{l}\left(\phi-\theta_{r}\right) \exp \left(-\frac{T-T_{F}}{T_{C}}\right)+\theta_{r}, T \leq T_{F}, \\ \phi, T>T_{F}\end{array}\right.$

where $\theta_{r}$ (dimensionless) denotes the residual water content when $T<<T_{F}, T_{F}$ denotes the liquidus or freezing point/temperature, $T_{C}$ denotes a characteristic temperature controlling the transition between the unfrozen and the frozen states, $\phi$ (dimensionless) denotes the (connected) porosity and $\phi-\theta_{r}$ denotes the maximum volumetric ice content at low temperatures. While the choice of eq. (2) is somehow empirical in nature, all the parameters entering this equation have a physical meaning. For instance, the temperature $T_{C}$ is somehow associated with the broadness of the pore size distribution. Eq. (2) is somehow equivalent to the capillary pressure curve in drainage and imbibition studies (see discussions Kurylyk \& Watanabe 2013, Pellet et al. 2016). A future analysis, which is outside the scope of this paper, will need to connect explicitly eq. (2) to the characteristics of the pore size distribution from first principles.

In freezing conditions, the value of $\alpha_{T}$ in eq. (1) remains valid (see discussion in Coperey et al. 2019b). The conductivity of the rock is given by Duvillard et al. (2018, see discussion in Appendix A):

$\sigma(T) \approx \theta^{m-1} \frac{\sigma\left(T_{0}\right)}{\phi}\left[1+\alpha_{T}\left(T-T_{0}\right)\right]$

where $m$ (dimensionless) denotes the cementation (porosity) exponent entering into Archie's (1942) law between the formation factor $F$ and the porosity $\phi$, that is, $F=\phi^{-m}$. An expression of the conductivity at the reference temperature $\sigma\left(T_{0}\right)$ is given in Appendix A. A typical value of $m$ is close to 2 and a typical range is between 1.5 and 2.5 (e.g. Coperey et al. 2019b, and references therein). Archie's law is also valid for fractured media (e.g. Cai et al. 2017). In eq. (3), we do not have to make any assumption regarding the importance of surface conductivity associated with the cation exchange capacity of the rock (see Duvillard et al. 2018; Coperey et al. 2019b, for details regarding this contribution). The effect of temperature below freezing conditions upon the electrical conductivity is therefore very strong, much stronger than changes associated with porosity and surface conductivity spatial changes in a given lithology (Coperey et al. 2019b).

Assuming that the cementation exponent $m$ is close to 2, an explicit relationship is obtained between the measured conductivity below the freezing point, $\sigma(T)$, and temperature, $T$ :

$\sigma(T) \approx\left[\left(\phi-\theta_{r}\right) \exp \left(-\frac{T-T_{F}}{T_{C}}\right)+\theta_{r}\right] \frac{\sigma\left(T_{0}\right)}{\phi}\left[1+\alpha_{T}\left(T-T_{0}\right)\right]$.

It is easy to show that we recover eq. (1) at and above the freezing temperature from eq. (4). Eq. (4) will be used to connect electrical conductivity to temperature in field conditions. Below the freezing temperature, temperature spatial variations are expected to be mimicked, to some level, by the electrical conductivity distribution.

\subsection{Normalized chargeability-temperature relationship}

In this paper, induced polarization is characterized by a single parameter called the normalized chargeability, which can be either obtained from the frequency dispersion of the conductivity data (for instance measured at two distinct frequencies, the so-called frequency effect) or from time-domain induced polarization by looking at the decay of the secondary voltage after the shutdown of the primary current (Kemna et al. 2012). Above the freezing temperature, the change in the normalized chargeability $M_{n}$ (in $\mathrm{S} \mathrm{m}^{-1}$ ) of a rock with temperature is controlled by the temperature dependence of the ionic mobilities, which is in turn controlled by the temperature dependence of the dynamic viscosity of the pore water. Like for the electrical conductivity, we have therefore (see Revil 2012 for a detailed description of the rationale behind eq. 5):

$M_{n}(T)=M_{n}\left(T_{0}\right)\left[1+\alpha_{T}\left(T-T_{0}\right)\right]$,

where $\alpha_{T}=0.021{ }^{\circ} \mathrm{C}^{-1}$, the reference temperature is $T_{0}=25^{\circ} \mathrm{C}$ and $M_{n}\left(T_{0}\right)$ denotes the normalized chargeability of the rock at the reference temperature. An explicit expression of this parameter will be given below. Using the model developed in Duvillard et al. (2018) and Coperey et al. (2019b), the dependence of the normalized chargeability in freezing conditions is given by:

$M_{n}(T) \approx\left[\left(\phi-\theta_{r}\right) \exp \left(-\frac{T-T_{F}}{T_{C}}\right)+\theta_{r}\right] \frac{M_{n}\left(T_{0}\right)}{\phi}\left[1+\alpha_{T}\left(T-T_{0}\right)\right]$.

Therefore, in freezing conditions, the temperature dependence of the normalized chargeability and the temperature dependence of the electrical conductivity are strictly the same. This is because of the specific dependence of the conductivity with the water content in freezing conditions is related to the segregation of salt in the liquid water phase. Thus, in contrast to what can be done in hydrothermal systems (Revil et al. 2019b), we cannot combine the normalized chargeability and electrical conductivity tomography to obtain independently the liquid water content except if we do the local gradient in salinity associated with freezing has totally diffused over time.

It should be remembered however that ice behaves as a dirty protonic semiconductor and therefore has its own polarization mechanism. In our work, we assume that the polarization in freezing conditions is essentially due to the decay of the double layer polarization at the solid-liquid interface. Assuming no addition response from the ice itself, the ratio of the normalized chargeability to the conductivity is independent of temperature since the dependence of $B(T)$ and $\lambda(T)$ are the same as well as the dependence with the water content. Therefore, we have

$\frac{M_{n}(T)}{\sigma(T)} \approx \frac{M_{n}\left(T_{0}\right)}{\sigma\left(T_{0}\right)}$. 
According to the dynamic Stern layer model developed by Revil (2012) and for conditions implying that the salt remains entirely segregated into the liquid pore water, the normalized chargeability and the conductivity are related to the water content $\theta$ (dimensionless) by

$M_{n}\left(T_{0}\right) \approx \phi \rho_{g} \lambda\left(T_{0}\right) \mathrm{CEC}$,

$\sigma\left(T_{0}\right) \approx \phi^{2} \sigma_{w}\left(T_{0}\right)+\phi \rho_{g} B\left(T_{0}\right) \mathrm{CEC}$,

respectively. In eqs (8) and (9), $\rho_{g}$ denotes the density of the grains (typically $2650-2900 \mathrm{~kg} \mathrm{~m}^{-3}$ ), $\sigma_{w}$ denotes the pore water conductivity (in $\mathrm{S} \mathrm{m}^{-1}$ ), CEC denotes the cation exchange capacity of the material (expressed in $\mathrm{C} \mathrm{kg}^{-1}$ or in meq/100 $\mathrm{g}$ with $1 \mathrm{meq} / 100 \mathrm{~g}=963.20 \mathrm{C} \mathrm{kg}^{-1}$ ), $B$ (in $\mathrm{m}^{2} \mathrm{~s}^{-1} \mathrm{~V}^{-1}$ ) denotes the apparent mobility of the counterions for surface conduction and $\lambda$ (in $\mathrm{m}^{2} \mathrm{~s}^{-1} \mathrm{~V}^{-1}$ ) denotes the apparent mobility of the counterions for the polarization associated with the quadrature conductivity, $B\left(\mathrm{Na}^{+}, 25^{\circ} \mathrm{C}\right)=3.1 \pm 0.3 \times 10^{-9} \mathrm{~m}^{-2} \mathrm{~s}^{-1} \mathrm{~V}^{-1}$ and $\lambda\left(\mathrm{Na}^{+}\right.$, $\left.25^{\circ} \mathrm{C}\right)=3.0 \pm 0.7 \times 10^{-10} \mathrm{~m}^{-2} \mathrm{~s}^{-1} \mathrm{~V}^{-1}$, and $m$ is the cementation exponent entering Archie's law. From eqs (8) and (9), the ratio between the normalized chargeability and the conductivity is given by

$\frac{M_{n}(T)}{\sigma(T)} \approx \frac{\rho_{g} \lambda \mathrm{CEC}}{\phi \sigma_{w}+\rho_{g} B \mathrm{CEC}}$.

When the conductivity of the rock is dominated by surface conductivity along the surface of the grains (i.e. $\phi \sigma_{w}<<\rho_{g} B \mathrm{CEC}$ ), this ratio is $R=\lambda / B$, which is in the range $0.08-0.12$, independent of the water content, frequency and temperature (Duvillard et al. 2018 obtained $R=0.08$; Coperey et al. 2019b, obtained $R=0.09$ ). When we have $M_{n}(T) / \sigma(T)<R$, this means that the bulk contribution of electrical conductivity (related to the pore water conduction $\sigma_{w}$ ) cannot be neglected.

\section{TEST SITE}

The lower Cosmiques ridge is located at $600-1000 \mathrm{~m} \mathrm{SSW}$ of the Aiguille du Midi (3842 m a.s.1.), on the northwestern side of the Mont Blanc massif (Fig. 1a), which spreads between France, Italy and Switzerland, and belongs to the Alpine external crystalline massifs. The ridge develops horizontally, on the French side of the massif, over a length of $400 \mathrm{~m}$ (Figs 1b and c) in the Mont Blanc granite from the Hercynian metamorphic series (Bussy \& von Raumer 1994). The extension of the SE face is 50-m-high and stands above the Glacier du Géant. It makes an angle of only $15^{\circ}$ with the vertical and has a rather smooth surface. This face is sometimes partially covered by snow. The NW face is about $350-\mathrm{m}$-high, $35^{\circ}$ with the vertical, and is highly rugged, allowing heterogeneous snow accumulation during a part of the year. The Mean Annual Rock Surface Temperature (MARST), modelled for the steep slopes of the Mont Blanc massif for the period 1961-1990 (Magnin et al. 2015c), is around $-4{ }^{\circ} \mathrm{C}$ on the NW face, and $-1{ }^{\circ} \mathrm{C}$ in the SE face of the lower Cosmiques ridge. A refuge was built during the period 19891991 on the top of the ridge (3613 m a.s.1.). It represents a popular location (hosting about 7000 people a year) since it is located along one of the main climbing route to reach the summit of the Mont Blanc. In 1998 August, a $600 \mathrm{~m}^{3}$ rockfall occurred right below the refuge and partly destabilized the infrastructure, which was closed for 8 months for reinforcement work (Fig. 1d; Ravanel et al. 2013).

\section{METHODS}

\subsection{Geophysical measurements}

\subsubsection{Field investigations}

The geophysical field surveys were performed both in 2016 October and 2019 September. A summary of these investigations is provided in Table 1. They extended from the foot of the SE face to the upper $64 \mathrm{~m}$ on the NW face, running below the refuge anchors and building (Fig. 2). Two 64-m-long cables (126-m-long profile) and a total of 64 electrodes (2-m-spacing) were connected to a resistivity meter (ABEM Terrameter SAS-4000 in 2016 and ABEM LS2 in 2019). We used 10-mm-diameter and 120-mm-long stainless steel electrodes for both surveys. The choice of the electrode is justified by the study of Labrecque \& Daily (2008). Warm salty water, conductive metallic grease and bentonite were used to improve the electrical contacts between the electrodes and the ground (Krautblatter \& Hauck 2007; Magnin et al. 2015b). The Wenner configuration was used because of its best signal-to-noise ratio thanks to its particular electrode configuration since the voltage electrodes $\mathrm{MN}$ are located in-between the current electrodes AB (e.g. Dahlin \& Zhou 2004; Kneisel 2006). During the surveys, only two electrodes had to be excluded due to their high contact resistances (higher than $10 \mathrm{k} \Omega$ ). Topography along the profile was extracted from a terrestrial laser scanning point cloud acquired in 2016 for the SE face and from a photogrammetric model acquired with a drone in 2019 on both faces of the ridge. Examples of the secondary voltage decay curves (expressed here in terms of the apparent chargeability integrated over time windows of $0.02 \mathrm{~s}$ ) are shown in Fig. 3. The induced polarization data exhibit a very good overall quality. We use $1 \mathrm{~s}$ for the period for the current injection. The secondary voltage is measured over a total time window of $0.22 \mathrm{~s}$. In this time window, the partial chargeabilities were sampled using 10 windows of $20 \mathrm{~ms}$. A dead time of $20 \mathrm{~ms}$ was used after the shutdown of the primary current. We performed up to four stacks for the resistivity measurements and two stacks for the induced polarization measurements to avoid accumulating polarization in the ground.

The data were inverted with the RES2DINV-3.54.44 software using a smoothness-constrained least-squares method and the standard Gauss-Newton method (see Loke \& Barker 1996, for details). The inversion was stopped at the third iteration when the convergence criterion was reached (i.e. default a value of 5 per cent in the relative change in the percentage root mean square (rms) error is used). The high rms error for the inversion results from some noise present in the data set because of the high contact resistance between the ground and the electrodes. That said, in presence of random noise in the data, a high rms error is not necessarily the criterion to say that the tomogram is not correct as discussed in Revil et al. (2008).

\subsubsection{Laboratory experiments}

In order to test the petrophysical model discussed in Section 2, we performed an electrical conductivity experiment on a rock sample collected in the field from an outcrop. The granite cubic core sample (labelled PAS1 below) was immersed in a temperature-controlled bath following the same protocol as in Duvillard et al. (2018) including for the sample preparation, temperature steps and complex conductivity measurements. Sample PAS1 was cut to get a $5-\mathrm{cm}$ large cube. Sample PAS1 was characterized by a porosity $\phi=$ 0.028 , a cation exchange capacity $\mathrm{CEC}=0.80 \mathrm{meq} / 100 \mathrm{~g}$, and a 


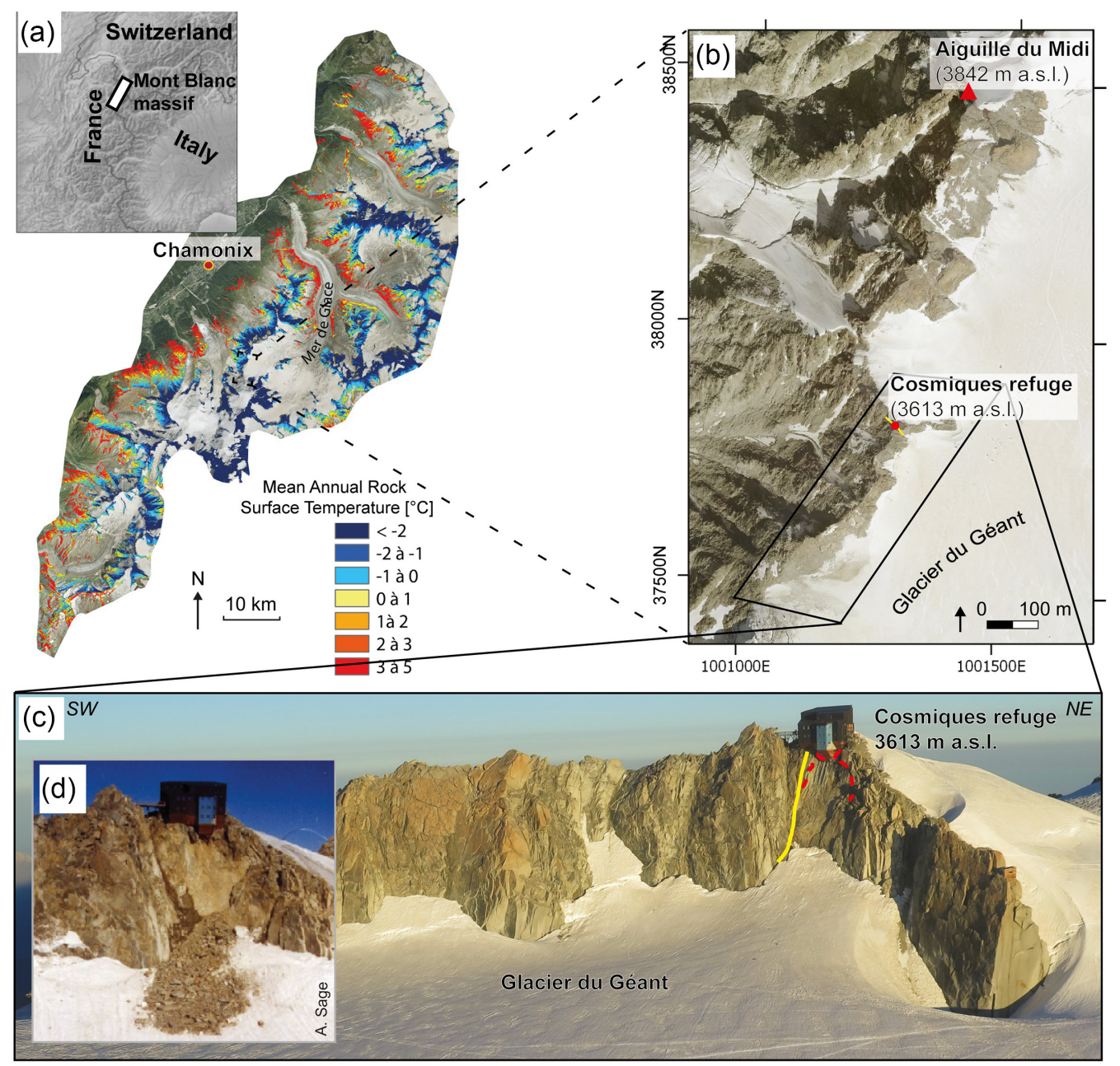

Figure 1. The Cosmiques refuge on the lower Cosmiques rock ridge (Mont Blanc massif, Western European Alps, France). (a) The Mont Blanc massif (here, the French side) is largely affected by the permafrost (Magnin et al. 2015a). (b) The lower Cosmiques ridge close to the Aiguille du Midi (3842 m a.s.1.). (c) South-east face of the lower Cosmiques ridge seen from the glacier du Géant (2016 September). The red dashed line underlines the scar of the 1998 rock fall while the yellow line indicates the position of the geophysical profile. (d) The Cosmiques rock fall of 1998 August $\left(\sim 600 \mathrm{~m}^{3}\right)$.

Table 1. Information regarding the electrical resistivity and induced polarization surveys. ER and IP stand for electrical resistivity and induced polarization, respectively.

\begin{tabular}{lccc}
\hline Profile & ER2016 & ER2019 & IP2019 \\
\hline Date of survey & October 5 & September 19 & September 19 \\
Electrode array type & Wenner 64XL & Wenner 64 & Wenner 64 \\
Excluded electrodes & 3 and 12 & 1 and 2 & 1 and 2 \\
Number of data points & 593 & 447 & 443 \\
Number of inverted points & 588 & 439 & 226 \\
Rms error & 29.5 & 19.2 & 14.2 \\
\hline
\end{tabular}

formation factor $F=499$ (for more details, see sample labelled COS in Coperey et al. 2019b). Before performing the laboratory measurements, the sample was dried during $24 \mathrm{hr}$ then saturated under vacuum with degassed water from melted snow taken in the field. The sample was left several weeks in the solution to reach chemical equilibrium before performing the laboratory measurements. The water conductivity at $25^{\circ} \mathrm{C}$ and at equilibrium was $0.0257 \mathrm{~S} \mathrm{~m}^{-1}$.

In addition, we used the laboratory data determined by Magnin et al. (2015b). This second sample (labelled G1 below) was collected in the same geological unit and saturated with tap water. Four nonpolarizing stainless steel electrodes were placed on the sample: two current electrodes (A and B) on the end-faces of the sample. Two voltage electrodes ( $\mathrm{M}$ and $\mathrm{N}$, separated by a distance of $8 \mathrm{~cm}$ ) were placed on the external side of the core sample.

The sample holder was installed in a heat-resistant insulating bag immersed in a thermostat bath (KISS K6 from Huber; $210 \times 400 \times 546 \mathrm{~mm}$; bath volume: 4.51 ). The temperature of this bath was controlled with a precision of $0.1{ }^{\circ} \mathrm{C}$. Glycol was used as heat carrying fluid and the complex conductivity measurements were carried out with the impedancemeter. The (in-phase) conductivity measurements shown here are at a frequency of $1 \mathrm{~Hz}$ but they were obtained in the frequency range $10 \mathrm{mHz}-45 \mathrm{kHz}$. The experimental data together with a fit of the data with eq. (1) (for 

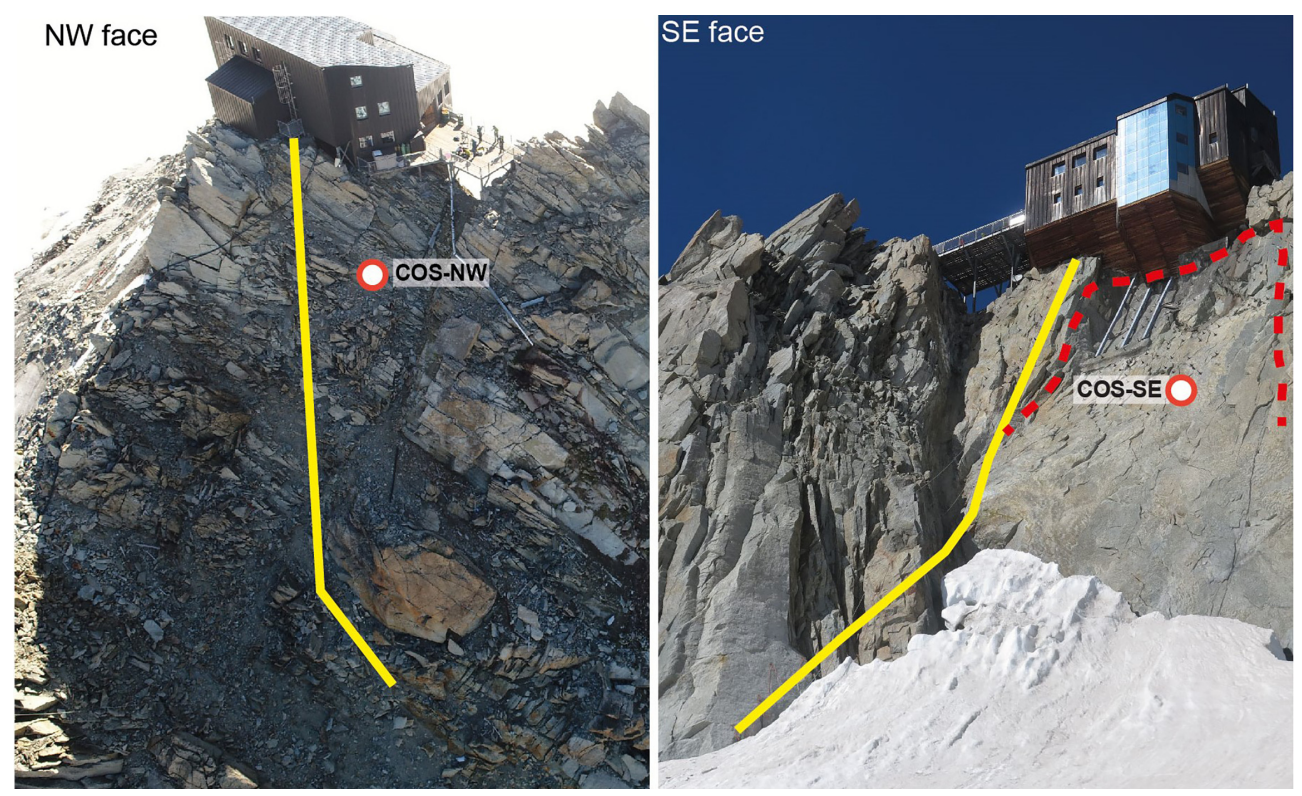

Figure 2. Location of the temperature sensors and the ERT profile below the Cosmiques refuge. The labels COS-NW and COS-SE denote the position of the temperature sensors. The yellow line shows the position of the geophysical profile while the red dashed line underlines the position of the 1998 rockfall scar.



Figure 3. Apparent chargeability (in $\mathrm{mV} \mathrm{V}^{-1}$ ) as a function of the elapse time (in s) after the shutdown of the primary current for four selected quadripoles ABMN. The plain lines denote exponential decay fits applied to the field data. The (A, B, M, N)-positions for the quadripoles are the following (expressed in metres) Quadripole1 $(4,16,8,12)$, Quadripole2 $(78,96,84,90)$, Quadripole3 $(90,120,100,110)$ and Quadripole4 $(56,86$, $66,76)$.

temperatures above the freezing temperature) and with eq. (4) (for temperatures below the freezing temperature) are shown in Fig. 4. We see that the model proposed in Section 2 is able to fit the data above and below the freezing temperature and provides therefore a bridge to connect electrical conductivity to temperature. The difference in the fitting parameters shows a bias due to the heterogeneity of the rock. That said, even with a high number of samples, the sampling may contain sampling bias that avoid a complete application of the optimized laboratory parameters to the field data. There may be also scaling issues. That said the laboratory experiments can be used to test the underlying physics and in the future we target a complete joint inversion of the conductivity and temperature fields to compensate for such bias.

Induced polarization measurements were done in the time domain with the sample core I.P. tester from GDD Inc. and using sample PAS1. We used the four electrodes approach, that is, current electrodes A and B are attached on the end faces of the cylindrical core while the potential electrodes $\mathrm{M}$ and $\mathrm{N}$ are fixed on the external side of the sample. We use four non-polarizing $\mathrm{Ag}-\mathrm{AgCl}_{2}$ electrodes with a spacing of $5 \mathrm{~cm}$. In order to avoid drying and short circuits at the electrodes, the sample was covered with insulating adhesive tape except at the position of the electrodes. Then, the sample was brought to different temperatures using a thermally controlled bath (Kiss K6 from Huber; see fig. 5 in Coperey et al. 2019b). The periods of the primary current injection were 1.0, 2.0 and $4.0 \mathrm{~s}$. The decay curve was recorded using 20 windows distributed in a 'Cole-Cole' configuration. More details about time-domain induced polarization measurements can be found in Kemna et al. (2012) and Revil et al. (2018). The results are shown in Fig. 5 and are fitted by eqs (5) and (6). We see that the model is able to fit the data very well.

From Figs 4 and 5 , we have $M_{n}\left(T_{0}\right)=5.9 \times 10^{-7} \mathrm{~S} \mathrm{~m}^{-1}$ and $\sigma\left(T_{0}\right) \approx 9 \times 10^{-5} \mathrm{~S} \mathrm{~m}^{-1}$. This yields $M_{n}(T) / \sigma(T)=0.007<<R$, which means in turn that surface conduction is not the dominating conduction mechanisms controlling the electrical conductivity of these rocks. Unaltered granite rock samples are usually characterized by a low specific surface areas and CEC, which could explain this observation.

\subsection{Rock surface temperature measurement and temperature modelling}

RST measurements allow to documenting the presence of permafrost by continuously measuring temperature for at least one full year (Gruber et al. 2004; Magnin et al. 2015a). Three RST sensors Geoprecision PT1000 with M-Log5W loggers (resolution: $0.01{ }^{\circ} \mathrm{C}$, accuracy $\pm 0,1^{\circ} \mathrm{C}$ with temperature recorded every $3 \mathrm{hr}$ ) 


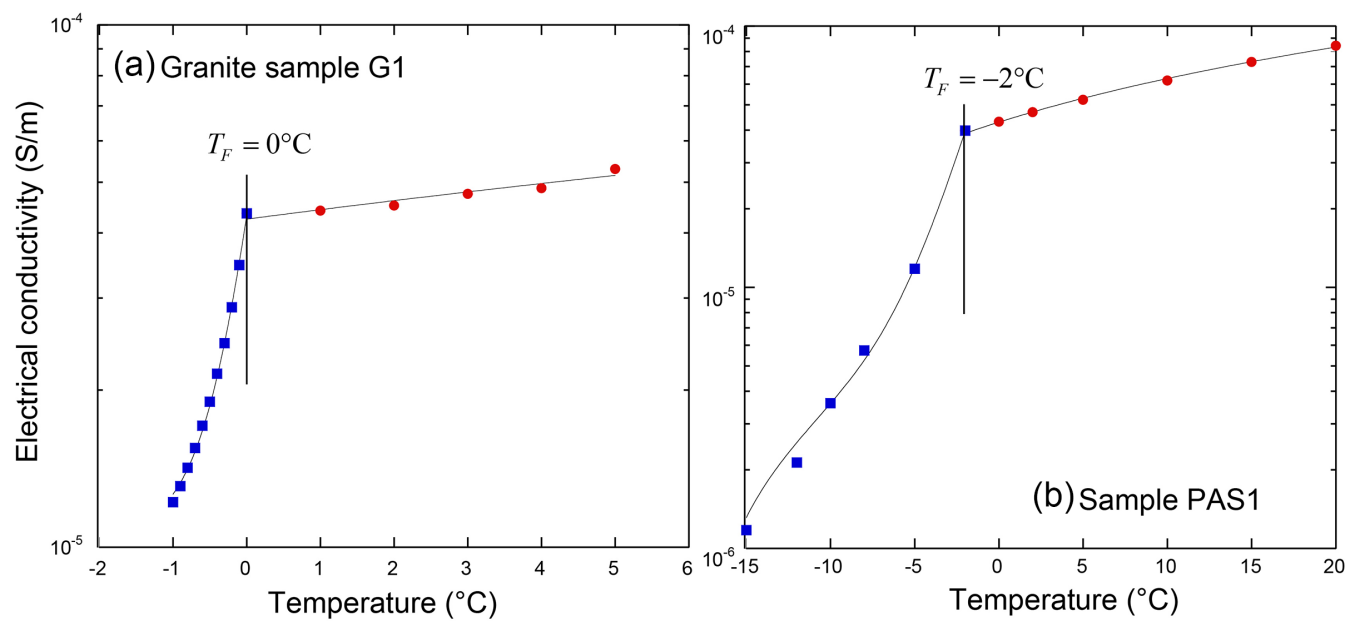

Figure 4. In-phase electrical conductivity data versus temperature for two granite core samples from the Cosmiques rock ridge and fit of the data with the model from Duvillard et al. (2018). (a) Granite sample G1 between -1 to $+5^{\circ} \mathrm{C}\left(T_{F}=0^{\circ} \mathrm{C}\right)$. The value of model parameters used to fit the measured data are $T_{C}=-0.41{ }^{\circ} \mathrm{C}, \phi=0.028, \theta_{r}=0.006$ and $\sigma\left(T_{0}\right)=8.8 \times 10^{-5} \mathrm{~S} \mathrm{~m}^{-1}$. (b) Granite sample PAS1 between -15 to $+20^{\circ} \mathrm{C}\left(T_{F}=-2^{\circ} \mathrm{C}\right)$. The value of the model parameters are $T_{C}=-2.9^{\circ} \mathrm{C}, \phi=0.028, \theta_{r}=0.002$, and $\sigma\left(T_{0}\right)=8.0 \times 10^{-5} \mathrm{~S} \mathrm{~m}^{-1}$. In both cases, the symbols denote the experimental data (red above the freezing temperature and blue below the freezing temperature), while the plain lines correspond to the fit of the model.

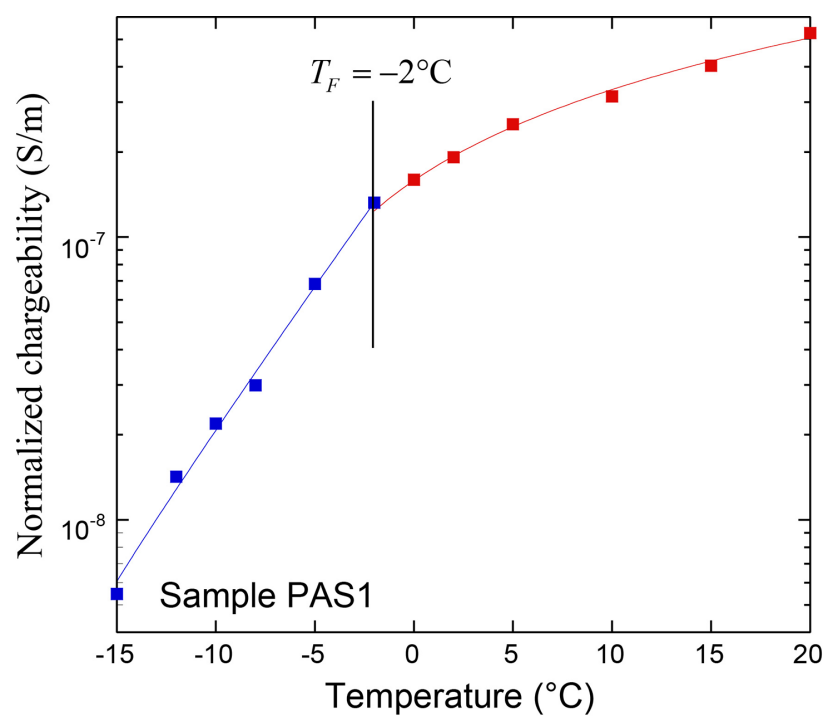

Figure 5. Normalized chargeability data versus temperature for the granite core sample PAS1 between -15 to $+20^{\circ} \mathrm{C}\left(T_{F}=-2^{\circ} \mathrm{C}\right)$. The value of the model parameters are $T_{C}=-5.4 \pm 0.7^{\circ} \mathrm{C}, \phi=0.028, \theta_{r}=0.001, M_{n}\left(T_{0}\right)$ $=2.9 \times 10^{-7} \mathrm{~S} \mathrm{~m}^{-1}$. We also obtained $\alpha_{T}=0.028 \pm 0.0007^{\circ} \mathrm{C}^{-1}$ above the freezing temperature. The symbols denote the experimental data (red above the freezing temperature and blue below the freezing temperature), while the plain lines correspond to the fit of the model.

were installed at a depth of $10 \mathrm{~cm}$ in 2016 July in the SE and NW faces and near the refuge foundation. The latter is not used in this study. The SE face sensor was installed $15 \mathrm{~m}$ below the refuge (at $3595 \mathrm{~m}$ a.s.1.), in the scar from the 1998 rock fall, and the NW face sensor was installed below the terrace of the refuge (at $3603 \mathrm{~m}$ a.s.1.) in a massive slab (Fig. 2). The NW face sensor was installed in a snow-free location, but the one on the SE face was installed on a rock wall on which snow accumulates in winter, covering the sensor. These sensors recorded RST at an hourly time step until 2018 September yielding time-series > 2 yr. The MARSTs allow a first approximation of the presence/absence of permafrost, negative values indicating the very likely presence of permafrost while values up to $3{ }^{\circ} \mathrm{C}$ might also indicate possible permafrost presence (Hasler et al. 2011). Such data can also be used to simulate permafrost evolution at depth by forcing a heat conduction model (e.g. Hipp et al. 2014).

To evaluate the occurrence of permafrost obtained from field electrical conductivity measurements, we simulate the bedrock temperature evolution during the years prior to measurements in order to assess the thermal state at the day of geophysical investigations in 2016 and 2019. To do so, we first reconstruct a timeseries of the daily RST (1993 January to 2016 July) at the SE and NW loggers locations by fitting a linear regression model between the measured RST and local air temperature records (data from Météo France). We tested the model fit with air temperature records from Chamonix (1042 m a.s.1.) and the Aiguille du Midi (3842 $\mathrm{m}$ a.s.1.). The best correlation between daily RST and daily air temperature was obtained with the Chamonix time-series for the NW sensor (0.88) and with the Aiguille du Midi time-series for the SE sensor ( 0.77 against 0.63 for the Chamonix time-series). Lower correlation between air temperature and RST on at the SE sensor is due to the presence of the snow cover in winter and the stronger variability in incoming solar radiation than at the NW sensor.

We then used air temperature time-series best correlated with the RST to reconstruct the RST prior to and after RST measurements by using the fitted regression model coefficients. Since the Aiguille du Midi weather records only start in 2007 February and because they are affected by several gaps during the period 2007-2019, data from the Chamonix time-series, which are continuous over time, were used to fill the gaps when reconstructing the RST time-series on the SE face. Two RST time-series are thus created for the NW and SE logger locations, starting in 1993 January (beginning of the continuous air temperature measurements by Météo France in Chamonix) and ending in 2019 September, with the measured values between 2016 July and 2018 September and the reconstructed values before and after. These time-series were used to force a MATLAB diffusive transient thermal model, the so-called CryoGRID2 model (Westerman et al. 2013). 
Table 2. Parameters used for the numerical simulation of the ridge temperature according to the model Legay et al. (submitted). The value of these petrophysical parameters have been fitted using the temperature data measured in three shallow wells.

\begin{tabular}{lc}
\hline Parameter & Value \\
\hline Thermal conductivity & $3.3 \mathrm{~W} \mathrm{~m}^{-1} \mathrm{~K}^{-1}$ \\
Porosity & 0.01 \\
Volumetric heat capacity & $2.10^{6} \mathrm{~J} \mathrm{~m}^{-3} \mathrm{~K}^{-1}$ \\
\hline
\end{tabular}

We solve a 1-D nonlinear diffusion equation over time by taking into account rock properties, air content, water/ice content and related thawing/freezing processes through latent heat consumption and release. Our goal is to determine the temperature distribution along a quasi-horizontal profile crossing the ridge with a length of $32.75 \mathrm{~m}$. In the original approach by Westerman et al. (2013), CryoGRID2 is used to model the temperature distribution in a vertical section in which only the upper surface has been exposed to air. Therefore, an RST time-series is used to impose the boundary condition at the top of the column (corresponding therefore to a Dirichlet boundary condition) and a thermal flux at the bottom (corresponding to a Neumann boundary condition).

Our model is however different from the modelling used in Westerman et al. (2013) since we model the temperature distribution across a ridge and we need to apply two RST time-series (the SE and NW temperature time-series) at both ends of the profile. In other words, in our case, we apply a Dirichlet boundary condition at each end of the 1-D profile to estimate the temperature distribution by solving the heat equation with CryoGRID2.

The equations are solved with a spatial resolution of $10 \mathrm{~cm}$ near the two end-points (i.e. from 0 to $1 \mathrm{~m}$ and from 31.75 to $32.75 \mathrm{~m}$ ). We use a discretization of $20 \mathrm{~cm}$ in the remaining part of the profile (i.e. from 1 to $31.75 \mathrm{~m}$ ). The simulation is performed between 1993 January 1 and 2019 September 18. Physical rock parameters were fitted using temperature time-series in three 10-m-depth boreholes at the Aiguille du Midi (Magnin et al. 2015a). They are reported in Table 2 and provide reasonable estimates for granites.

Legay et al. (submitted) have calculated a model uncertainty (standard deviation) of $0.55^{\circ} \mathrm{C}$ according to the error distribution (difference between the modelled and measured temperature values in the boreholes). In addition, uncertainties in the inputs of the model must be considered; the loggers give an uncertainty of $\Delta_{95}$ per cent $=1.1^{\circ} \mathrm{C}$ for the measured temperatures time-series (NW and SE series).

\section{RESULTS}

\subsection{Electrical conductivity and normalized chargeability tomograms}

Electrical conductivity tomograms acquired in 2016 and 2019 show a vertical distribution of the conductivities with rather low conductivity values $\left(<10^{-4} \mathrm{~S} \mathrm{~m}^{-1}\right)$ below the NW face and higher values below the $\mathrm{SE}$ face $\left(>10^{-4} \mathrm{~S} \mathrm{~m}^{-1}\right)$. The chargeability tomogram acquired in 2019 shows a similar vertical distribution between the NW face and SE face. The two colour scales are adjusted with respect to the $0^{\circ}$ value to the conductivity values (between $10^{-4}$ and $10^{-5}$ $\mathrm{S} \mathrm{m}^{1}$ ) or normalized chargeability values (between $10^{-6}$ and $10^{-7}$ $\mathrm{S} \mathrm{m}^{1}$ ) observed during the laboratory experiments (Figs 4 and 5). This suggests that permafrost presence is restricted to the NW face with a vertical permafrost limit below the hut and the absence of permafrost below the SE face (Figs 6 and 7). A temperature versus depth profile is shown in Fig. 8 indicating a freezing temperature around $0{ }^{\circ} \mathrm{C}$. At this stage, only a semi-quantitative interpretation of the profiles is possible, as previously carried out in previous studies analysing electrical conductivity tomograms in rock walls (Krautblatter \& Hauck 2007; Magnin et al. 2015b; Keuschnig et al. 2017). Thus, at the current stage, it is not possible to assess how close to the thawing point the permafrost is.

\subsection{Petrophysical modelled temperature distribution in the ridge}

In order to convert the electrical conductivity distribution into temperature fields, we consider the following values of the model parameters entering equations (4): $T_{C}=-0.41^{\circ} \mathrm{C}, \phi=0.028$ and $\theta_{r}=0.006$ based on the experimental data (Fig. 4). In addition, we consider $T_{F}=0^{\circ} \mathrm{C}$ based on borehole data (Fig. 8). The experimental data with a lower freezing temperature may be due an incomplete equilibrium reached in the core sample between each temperature drop. Based on our experimental data, the value of the characteristic temperature $T_{C}$ entering eq. (4) should be taken in the range $-2.9^{\circ} \mathrm{C} \leq T_{C} \leq-0.4^{\circ} \mathrm{C}$. This range is likely due to the heterogeneity of the rock. The last step is to determine the value of the conductivity of the rock at the reference temperature, that is, $\sigma\left(T_{0}\right)$. We first determine the value of $\sigma\left(T_{F}=0^{\circ} \mathrm{C}\right)$ from the electrical conductivity distribution resulting from the electrical conductivity tomogram. This value is obtained as follows.

Note that there is a strong drop in the gradients of the fits to the $\log$ (conductivity) versus temperature data above and below the freezing temperature. Above the freezing temperature, the gradient is small, thus, for uniform temperature sampling, there will be more values in any conductivity range. Below the freezing temperature, the gradient is much steeper, thus in the same size conductivity range there will be fewer values. As below the freezing temperature, the curve starts to decrease in gradient with decreasing temperature there subsequently starts to be an increase in the number of uniformly distributed temperature points in a given conductivity range. Hence, we get a minimum in the histogram. The same is expected for the field data if the temperature sampling is uniform enough. What do we mean by 'uniform enough' for the field data? In the field, the temperature field is smooth because acting as a solution of a diffusion equation with a small variance in the thermal diffusion coefficient. The electrical conductivity distribution resulting from the least-squares inversion of the field data with a Laplacian as regularizer is also a smooth field. It is therefore quite legitimate to expect also a minimum in the conductivity distribution.

The notch in the conductivity distribution is clearly identified in Figs 9 and 10 for both laboratory and field data, acquired in 2016 and 2019. This yields $\sigma\left(T_{F}=0^{\circ} C\right)=5 \times 10^{-5} \mathrm{~S} \mathrm{~m}^{-1}$ for the field data. Then, this value is converted to the reference temperature of $25^{\circ} \mathrm{C}$ to be used in eq. (4). Using eq. (1), we obtain $\sigma\left(T_{0}\right)=8 \times 10^{-5} \mathrm{~S} \mathrm{~m}^{-1}$, therefore in agreement with the values determined independently from the curve fitting shown in Fig. $4\left(\sigma\left(T_{0}\right)=8.8 \times 10^{-5} \mathrm{~S} . \mathrm{m}^{-1}\right.$ for sample $\mathrm{G} 1$ and $\sigma\left(T_{0}\right)=8.0 \times 10^{-5} \mathrm{~S} \mathrm{~m}^{-1}$ for sample PAS1).

With these values, two temperature distributions are shown in Fig. 11 for $T_{C}=-2.2$ and $-0.4^{\circ} \mathrm{C}$, respectively. These results show a relative increase of the lowest temperature between 2016 and 2019 , according to the two sample (sample $\mathrm{G} 1,-1.7^{\circ} \mathrm{C}$ in 2016 , then $-1{ }^{\circ} \mathrm{C}$ in 2019 ; sample PAS $1,-10{ }^{\circ} \mathrm{C}$ in 2016 , then $-6{ }^{\circ} \mathrm{C}$ in 2019), suggesting permafrost degradation (warming) within this 3 yr period. 

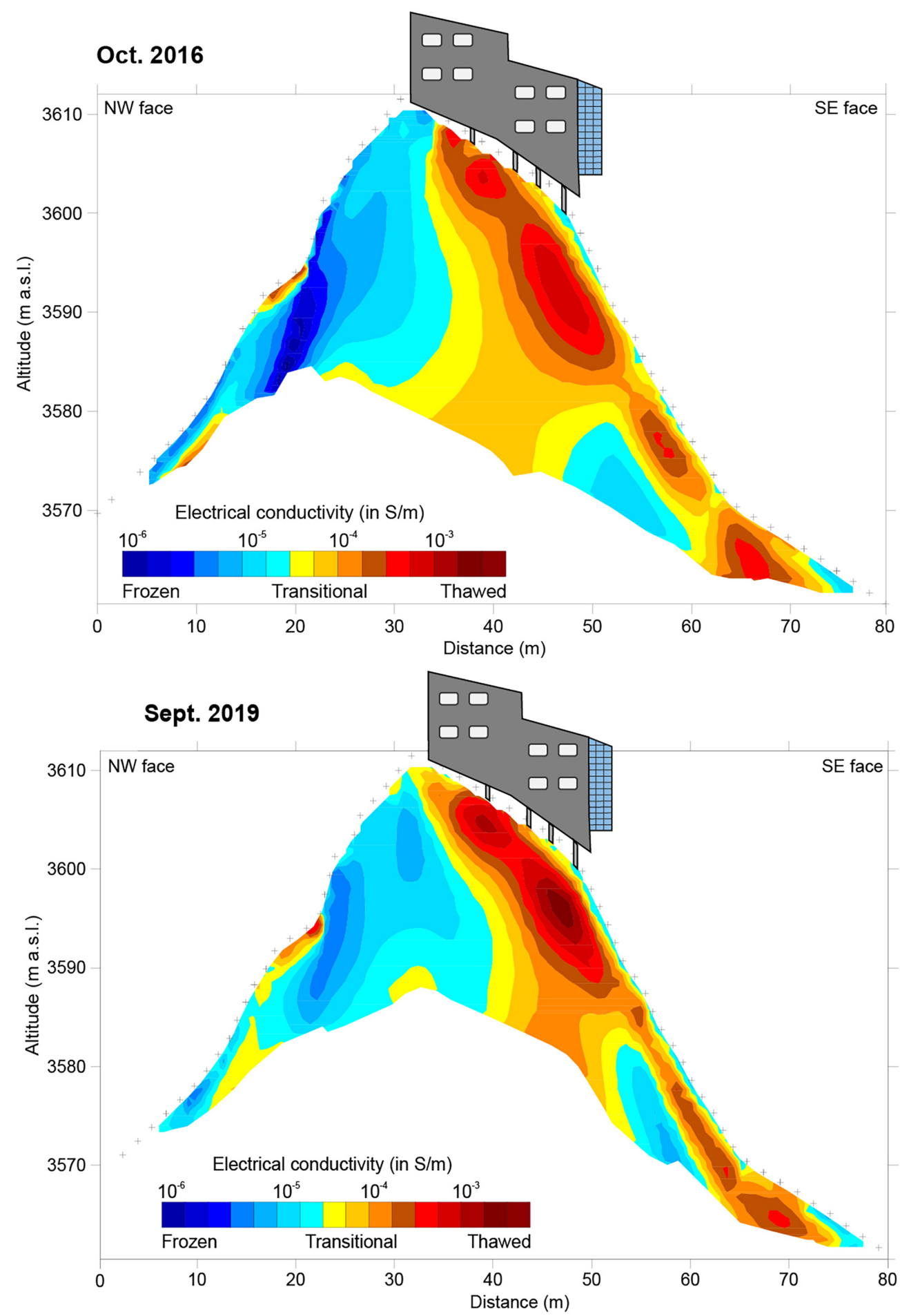

Figure 6. Electrical conductivity tomography (in $\mathrm{S} \mathrm{m}^{-1}$ ) of the rock ridge below the Cosmiques refuge in 2016 and 2019 . We use cold colours for the low conductivity values presumed to correspond to the rock mass undergoing freezing conditions. The warm colours corresponds to the rock mass above freezing conditions.

\subsection{Measured and modelled bedrock temperature}

The MARST during the measurement period (from 2016 to 2018 August 15) was $-3.7^{\circ} \mathrm{C}$ on the NW face and $+2.4^{\circ} \mathrm{C}$ on the SE face. This is in agreement with suggestion from the petrophysical models, which displays permafrost conditions below the NW face but not below the SE face. Temperatures simulated at depth with CryoGRID2 are presented in Fig. 12 for the period from 2009
January 1 to 2019 September 18. We use a 1-D approximation accounting for the fact that the ridge can be approximated to be infinite in the normal direction and that the top of the ridge is still far from the line of interest. They show a depth of the permafrost in the $\mathrm{NW}$ face around $-15 \mathrm{~m}$ with temperature between $-2 /-3{ }^{\circ} \mathrm{C}$ during the ERT and IP acquisition in 2016 October and 2019 September. This simulation indicates warm permafrost in the NW face, probably 


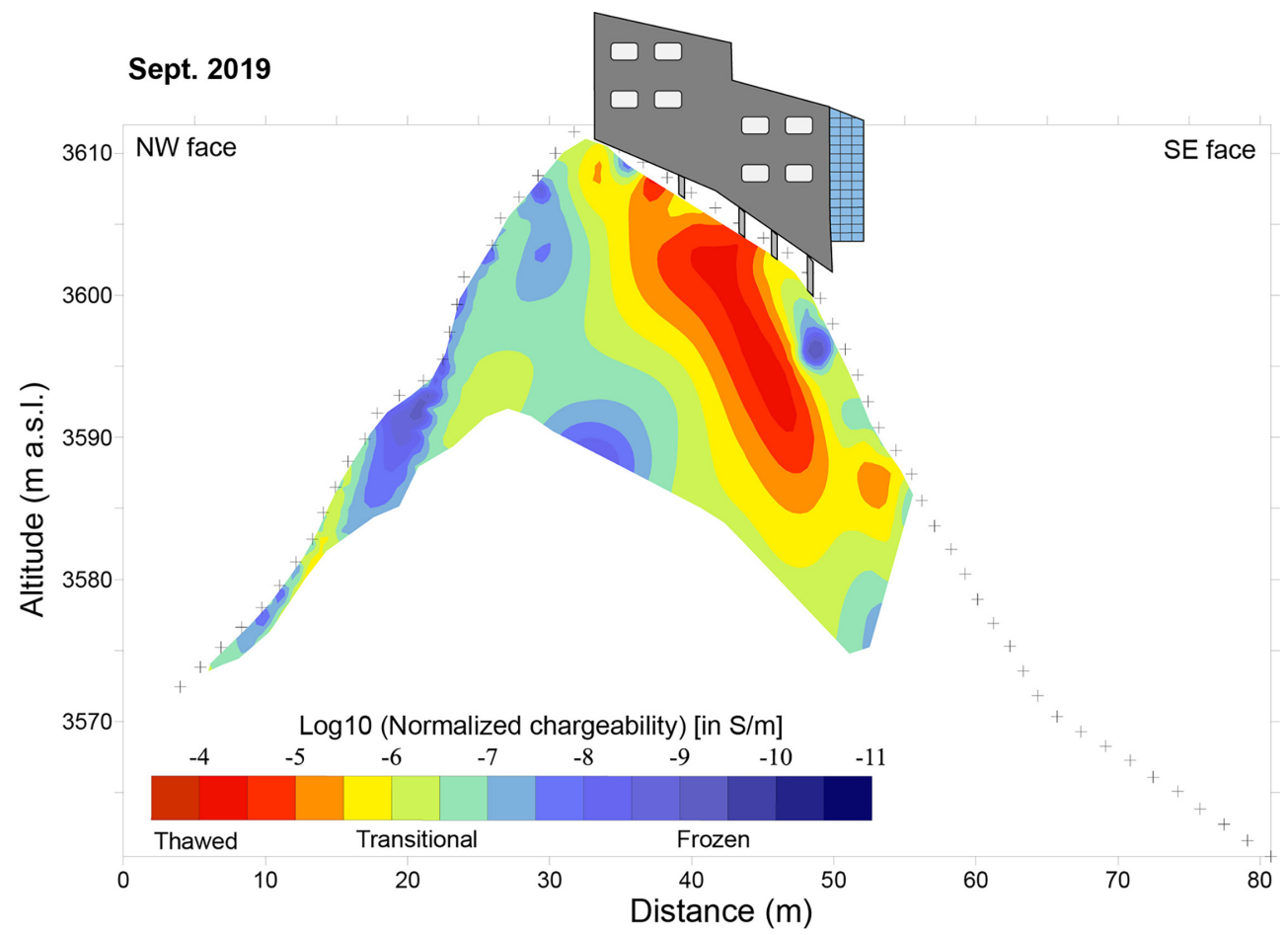

Figure 7. Normalized chargeability tomograms (in S m ${ }^{-1}$ ) of the rock ridge below the Cosmiques refuge in 2019. Tomogram is smaller in SE face due to the lack of inverted data points. Note that some low values in the normalized chargeability close to the surface in the SE side of the ridge may due to the low water content of the rock.

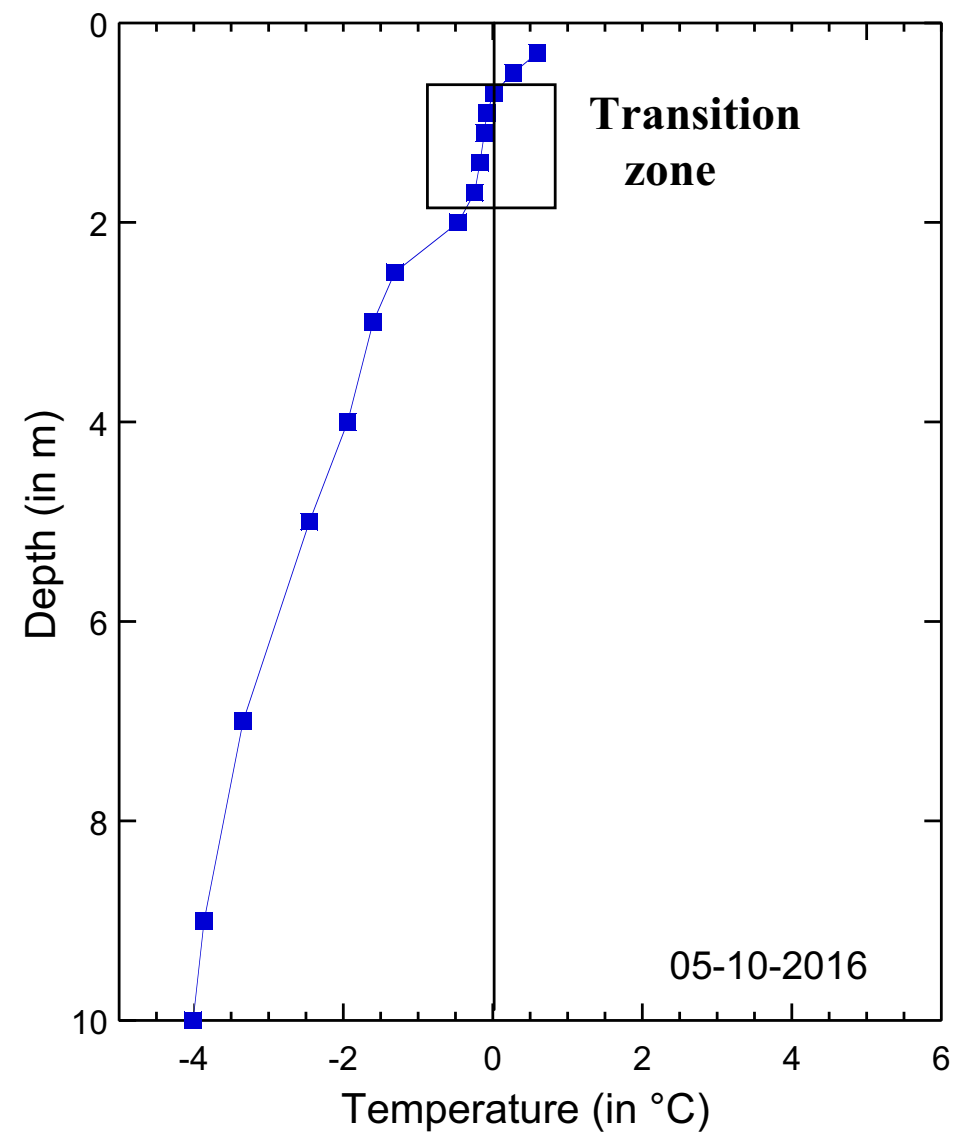

Figure 8. Temperature as a function of depth for the borehole located on the NW face of the ridge in the Aiguille du Midi (3738 $\mathrm{m}$ a.s.1.). Note that the transition zone defined the freezing temperature as being just below $0^{\circ} \mathrm{C}$. 
(a) Laboratory data

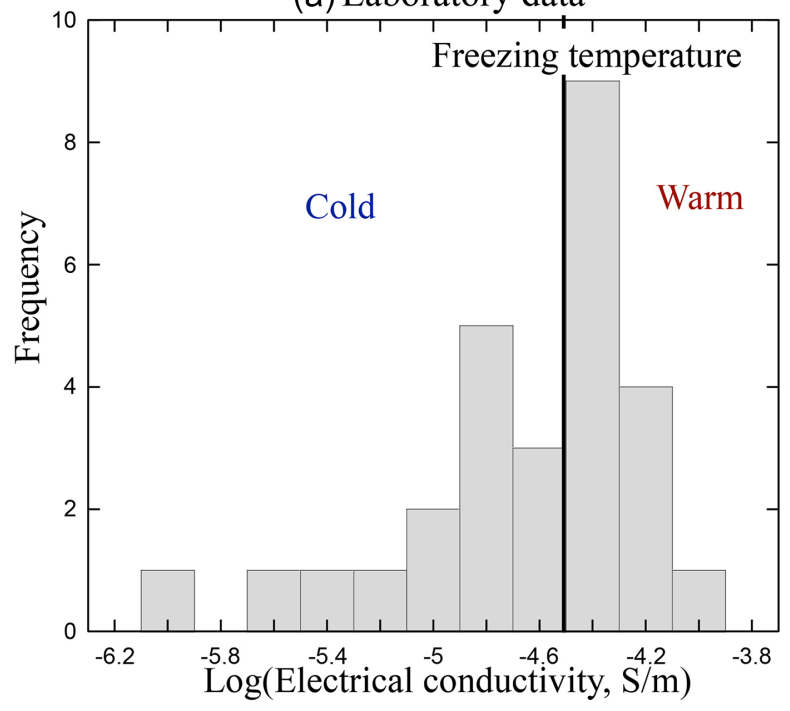

(b) Field data

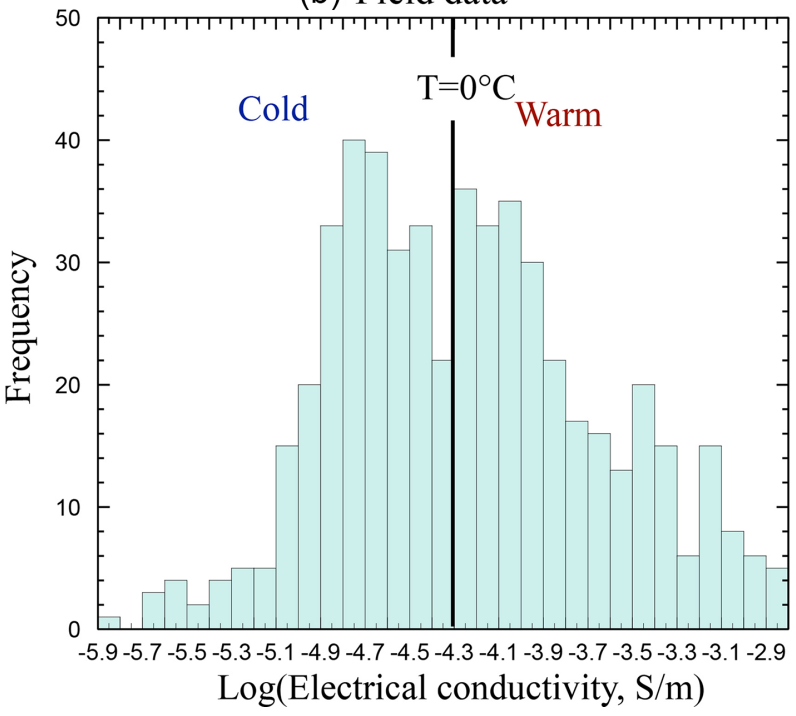

Figure 9. Distribution of the electrical conductivity. (a) Laboratory data using all the measurements for the two core samples shown in Fig. 4. (b) 2016-field data from the electrical conductivity tomogram. The observed minimum in the distribution is used to define the value of the electrical conductivity of the material at the freezing temperature. In the field data, we obtain $\sigma\left(T_{F}=0^{\circ} \mathrm{C}\right)=5 \times 10^{-5} \mathrm{~S} \mathrm{~m}^{-1}$ (obtained from the vertical plain line associated with the minimum in the conductivity distribution). The consistency of this value with the value obtained from the laboratory data validates the approach.

in thawing phase with the zero degree isotherm appears to be moving towards the NW face over the considered time period.

\section{DISCUSSION}

\subsection{Comparison between geophysics and numerical modelling}

When we compare the negative temperature converted from the geophysics (petrophysical model only used under $0{ }^{\circ} \mathrm{C}$ ) with temperature simulated with the numerical model, we observe that the NW face of the rock ridge is frozen with both methods, in 2016 and 2019. We recall that the geophysical data can only be used to

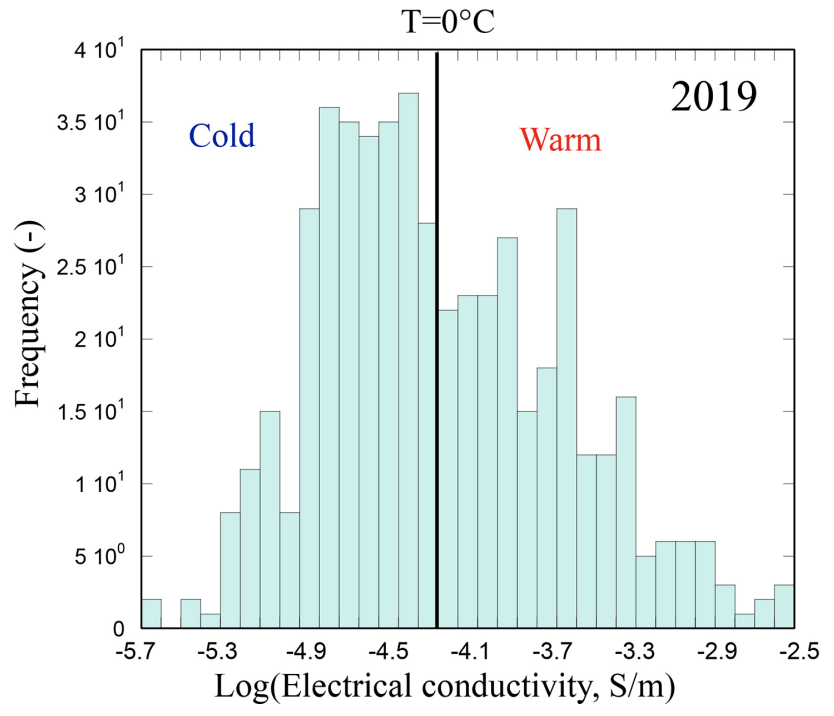

Figure 10. Distribution of the electrical conductivity for the 2019 field data. We observe higher values for the conductivity with respect to the distribution taken in 2016 (see Fig. 9).

assess the temperature in the frozen portion of the ridge; above the freezing temperature, the effect of heterogeneity is stronger than the effect of temperature regarding their effects on the conductivity field. Fig. 11 confirms a good correlation between the frozen and unfrozen parts of the ridge between the geophysical prediction and the numerical modelling. The temperature distribution with $T_{c}=$ $-2.2^{\circ} \mathrm{C}$ (sample PAS1 saturated with snowmelt; Fig. 4a) suggests that the bedrock temperature is between -2 and $-4{ }^{\circ} \mathrm{C}$ in 2016 and 2019 at a depth of $10 \mathrm{~m}$ in the NW face while the temperatures simulated with the numerical model is $-2{ }^{\circ} \mathrm{C}$. The determination of the temperature distribution assuming $T_{c}=-0.36^{\circ} \mathrm{C}$ (Fig. 4b) suggests a bedrock temperature of $-0.5^{\circ} \mathrm{C}$ at $10 \mathrm{~m}$ depth in 2016 and 2019 while the numerical simulation suggests $-2{ }^{\circ} \mathrm{C}$. Therefore, the numerical modelling shows that the NW face of the rock ridge is frozen (permafrost conditions) with a temperature around $-2{ }^{\circ} \mathrm{C}$; which is very consistent with the interpretation of the geophysical data from the sample PAS1 (with $T_{c}=-2.9^{\circ} \mathrm{C}$, see Fig. 11).

\subsection{Uncertainty}

In the previous section, we made a qualitative comparison between the prediction of the geophysical data using the petrophysical model discussed in Section 2 and the 1-D numerical model. We avoided a direct comparison because, in our opinion, both approaches contain sources of uncertainties. For the numerical model, the main sources of errors are associated with (1) uncertainties associated with the dimensionality of the numerical model, (2) uncertainties in the value of the petrophysical parameters used in the heat equation, (3) uncertainties in the boundary conditions and (4) uncertainties in the numerical modelling itself. For instance, CryoGRID2 assumes that the material properties are uniform and does not account for specific heat flows along the bedrock fractures (convection from air ventilation and advection from snowmelt infiltration) nor variability in water/ice content which affects freezing and thawing patterns through latent heat fluxes. It also neglects the vertical component of the ridge geometry but this is presumably of minor effect as the main lateral heat flux (Noetzli et al. 2007; Magnin et al. 2017a) between the SE and NW faces is accounted for. 

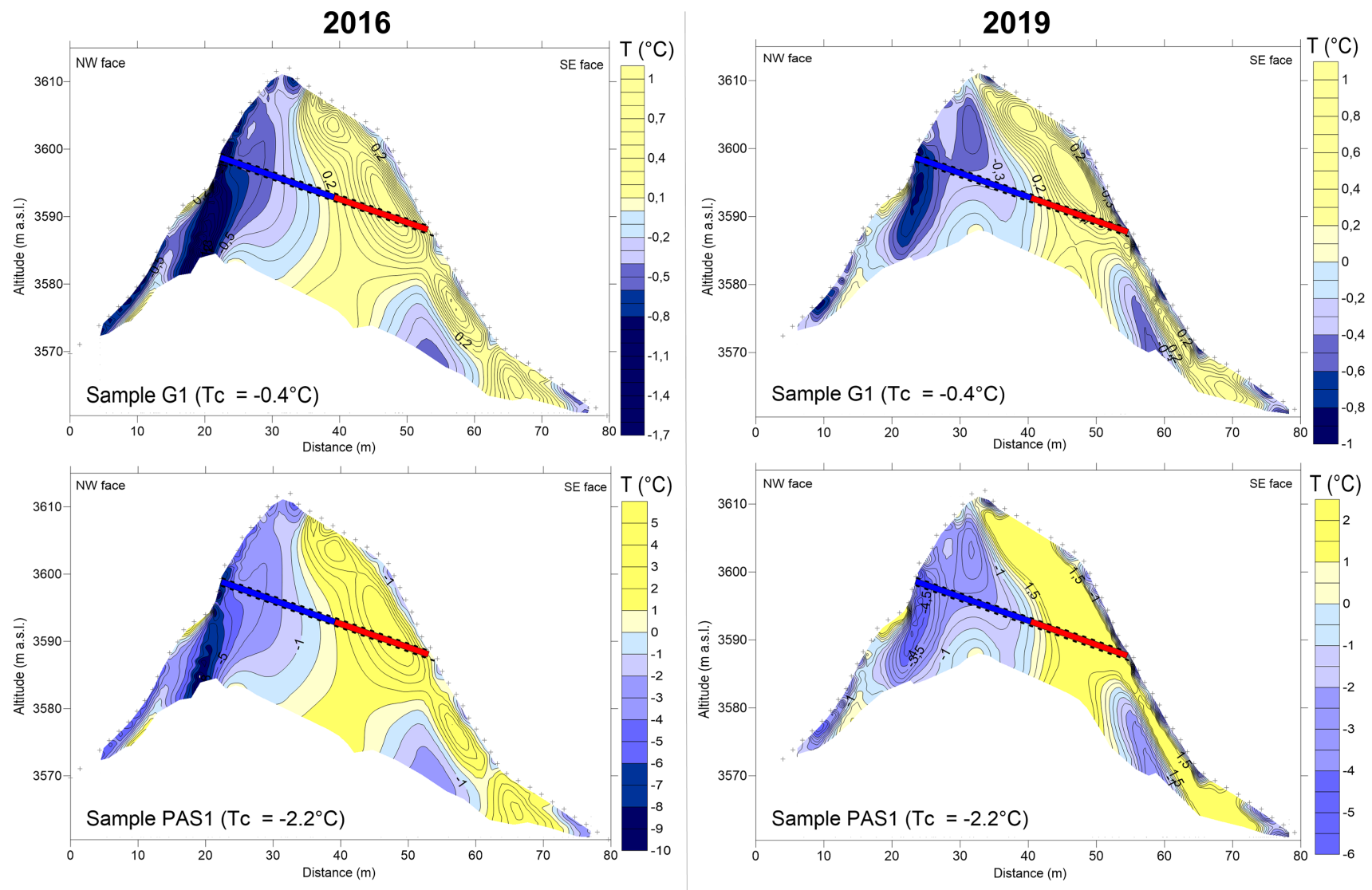

Figure 11. Distribution of the temperature determined from the electrical conductivity distribution for the 2016 and 2019 tomograms. Distribution obtained with the characteristic temperature $T_{C}=-0.4$ and $-2.2^{\circ} \mathrm{C}$. Permafrost is inferred below the NW face of the rock ridge. We also show the pseudo-horizontal section of length $32.75 \mathrm{~m}$ crossing the ridge and used for the numerical modelling of the temperature field. The blue portion of this profile denotes the frozen section, while the red portion indicates the zone above the freezing temperature. Note the agreement between the geophysical prediction and the numerical model.

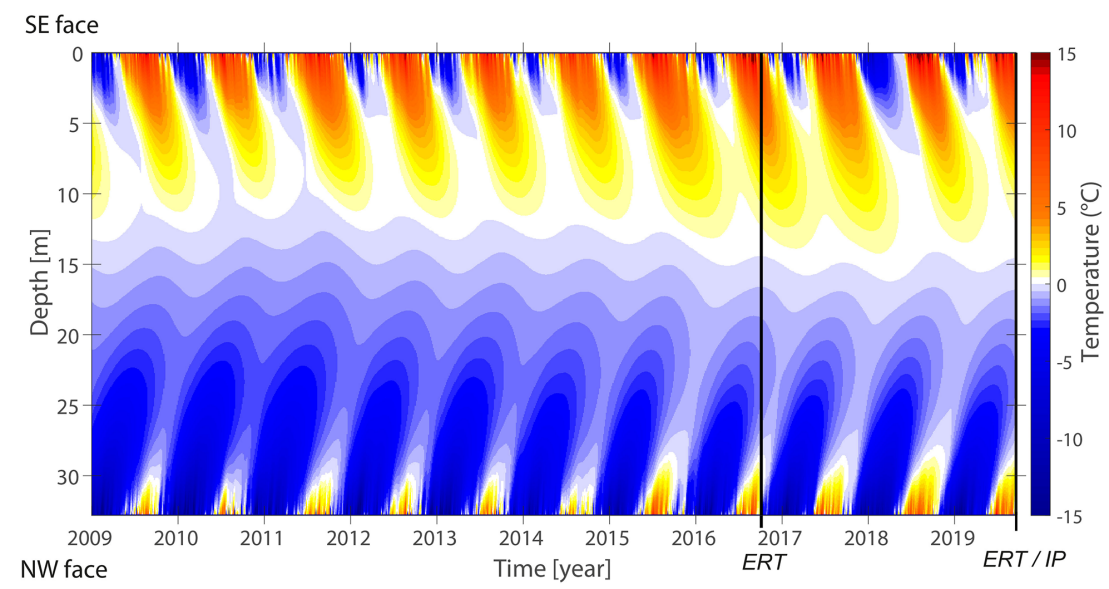

Figure 12. Modelled daily rock temperature along a horizontal section of $32.75 \mathrm{~m}$ crossing the ridge (as shown in Fig. 11). The SE face of the rock ridge corresponds to the top of the section, while the NW face corresponds to the bottom part of the section. The temperature distribution is modelled by applying the observed thermal boundary conditions as explained in the main text. The two vertical lines correspond to the acquisition dates (in 2016 and 2019) of the geophysical data (ERT stands for electrical resistivity tomography, while IP stands for induced polarization). We see that a large portion of the ridge is expected to be frozen. Note that zero degree isotherm appears to be moving towards the NW face over the time period.

Regarding the geophysical data, sources of errors are associated with (1) uncertainties in the inversion of the geophysical data (choice of the regularization term in the cost function), (2) uncertainties in the geophysical data and (3) uncertainties in the parameters entering in the petrophysical model. A complete analysis of the uncertainties associated with the two approaches is out of the scope of this paper. This being said, a future investigation will focus on a temperature tomogram that will combine 2-D numerical modelling of the heat equation with the geophysical data to get a balance in terms of combining the two types of information. 


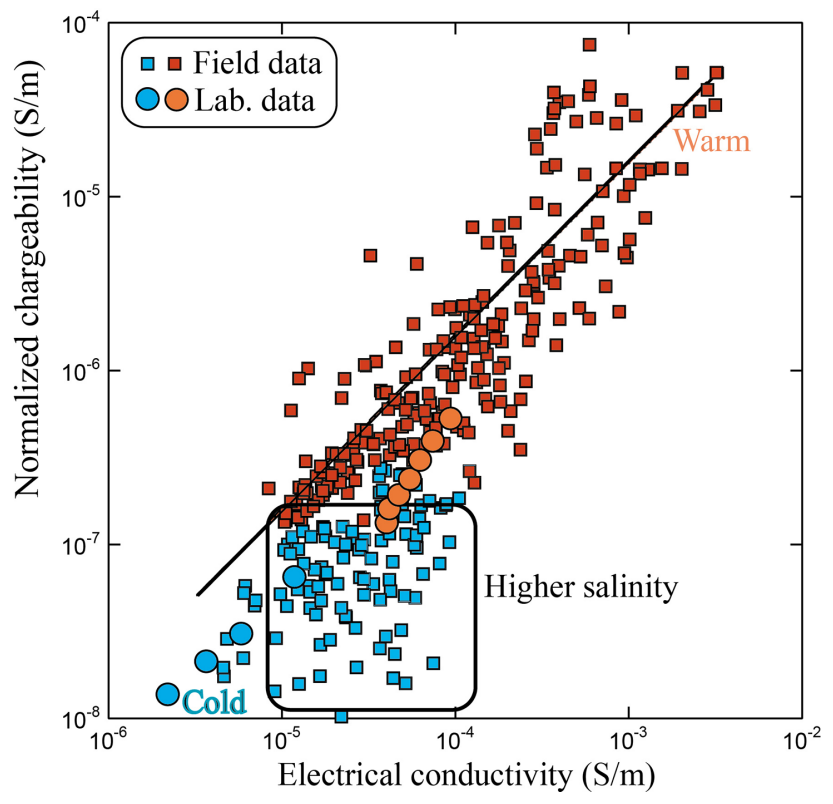

Figure 13. Normalized chargeability versus electrical conductivity. Comparison between the field and laboratory data (PAS1). The colour code is blue for the cold values below the freezing temperature and red above the freezing temperature. The plain line corresponds to the best fit of the field data (with a slope of $0.016, r=0.69$, fit forced through the origin of the coordinates). The small value of the slope (smaller than $R=0.08$ indicates that the electrical conduction process is mostly dominated by the pore water contribution.

\subsection{Influence of surface conductivity}

In absence of metallic particles, the electrical conductivity of a rock sample has two contributions: a bulk conductivity associated with the pore water in the connected pore space and a surface (interfacial) conductivity associated with conduction in the electrical double-layer coating the surface of the grains. The third point we want to discuss is the influence of this surface conductivity in the overall electrical conductivity of the rock ridge. With the laboratory data, we already demonstrated that surface conduction is likely not dominant in explaining the conductivity of the granite from the ridge. What about the field data? Fig. 13 displays the field and laboratory data in terms of normalized chargeability versus conductivity. It clearly shows that the slope $(0.016<<R=0.10)$ is such that the conductivity is dominated with the pore water conductivity rather than by the surface conductivity. This is an important point in interpreting electrical conductivity tomograms in field conditions.

\subsection{How useful is induced polarization?}

In our model, somehow partially validated in this paper and both in Duvillard et al. (2018) and Coperey et al. (2019b), the conductivity and the normalized chargeability have the same temperature dependence above and below the freezing temperature. This is true only if the conduction and polarization process are related to ionic processes occurring in the liquid pore water phase and at the interface between this phase and the solid phase. In this case, induced polarization is only useful in assessing the contribution of surface conductivity with respect to the total conductivity of the material. However there is potentially another polarization process occurring in the material as briefly mentioned in Duvillard et al. (2018). Ice is a dirty protonic semi-conductor and as such, it could contribute to the polarization of the material. This could potentially explain the discrepancy in the trend below the freezing temperature between the normalized chargeability (Fig. 5) and the conductivity (Fig. 4b) for sample PAS1. Future works will be focused on elucidating the polarization mechanism using the work done for semi-conductors by Revil et al. (2015a,b). In addition, induced polarization could be used to image the relaxation time, another key parameter of porous media (see Revil et al. 2019a). We let this point for a future investigation.

\section{CONCLUSIONS}

Assessing permafrost distribution in steep high-Alpine rock walls and ridges is challenging due to the highly variable temperature distribution, largely governed by the micro- to meso-topographical settings and related topoclimatic controls. Point-scale temperature measurements and temperature models are therefore limited. In this study, we proposed to assess the 2-D temperature distribution of a rock ridge by mean of electrical conductivity tomography and a petrophysical model parametrized with a calibrated freezing curve in the laboratory. Electrical conductivity normalized chargeability measurements are performed on two rock samples from the test site. The parametrized petrophysical model applied to electrical conductivity data performed over the rock ridge provides realistic temperature fields for the lower Cosmiques ridge. Warm permafrost is inferred right below the NW face and the absence of permafrost is inferred right below the SE face and below the refuge. The resulting temperature extracted from geophysics, with sample saturated with melted snow, advert temperature around $-2{ }^{\circ} \mathrm{C}$, which is consistent with the numerically simulated temperature. This approach needs to be tested on other areas to better assess the asset and limits of the proposed method. An in-depth analysis of the relationship between the conductivity and the normalized chargeability indicates that the conductivity is dominated here by the bulk conductivity rather than by the surface conductivity associated with conduction in the electrical double later coating the grains. In the future, we propose to develop a joint inversion framework using hard and soft temperature data honoring the physics dictating the temperature distribution in the rock ridge.

\section{ACKNOWLEDGEMENTS}

This research is part of the FEDER POIA 'PermaRisk' project. P-AD's Post-doc is supported by a grant from FEREC foundation by the STAAF project. The authors thank E. Malet, M. Marcer, M. Rameau, C. Mörtl and G. Marsy for their help on the field. We thank E. Veyrat-Durebex and L. Ravanel, the two successive keepers of the Cosmiques refuge, as well as the alpine guides of the Compagnie des Guides de Chamonix for sharing their knowledge of the area. We thank S. Westermann (Univeristy of Oslo, Norway) for sharing the CryoGRID2 program. We thank A. Soueid Ahmed, G. Menard and C. Lambiel for fruitful discussions on the topic of this paper and Malcolm Ingham and two anonymous referees for their constructive comments together with the associate editor. The data used in this study are available by sending a message to the corresponding author of the paper or to the first author. The work of AR is supported by I-RISK, Indura, the Région Auvergne-RhôneAlpes and the European Union (FEDER). 


\section{REFER EN CES}

Abdulsamad, F. et al., 2019. Complex conductivity of graphitic schists and sandstones, J. geophys. Res., 124, 8223-8249.

Archie, G., 1942. The electrical resistivity log as an aid in determining some reservoir characteristics, Trans. AIME, 146, 54-62.

Biskaborn, B.K. et al., 2019. Permafrost is warming at a global scale, Nat. Commun., 10, doi:10.1038/s41467-018-08240-4

Boeckli, L., Brenning, A., Gruber, S. \& Noetzli, J., 2012. Permafrost distribution in the European Alps: calculation and evaluation of an index map and summary statistics, Cryosphere, 6, 807-820.

Bussy, F. \& von Raumer, J.F., 1994. U-Pb geochronology of Palezoic magmatic events in the Mont-Blanc crystalline massif, Western Alps. Swiss Bull. Mineral. Petrol., 74, 514-515.

Cai, J., Wei, W., Hu, X. \& Wood, D.A., 2017. Electrical conductivity models in saturated porous media: a review, Earth Sci. Rev., 171, 419-433.

Coperey, A., Revil, A. \& Stutz, B., 2019a. Electrical conductivity versus temperature in freezing conditions: a field experiment using a basket geothermal heat exchanger, Geophys. Res. Lett., 46. https://doi.org/10.1029/2019GL084962.

Coperey, A., Revil, A., Abdulsamad, F., Stutz, B., Duvillard, P.A \& Ravanel, L., 2019b. Low frequency induced polarization of porous media undergoing freezing: preliminary observations and modeling, J. geophys. Res., 124, doi:10.1029/2018JB017015.

Dahlin, T. \& Zhou, B., 2004. A numerical comparison of 2D resistivity imaging with 10 electrode arrays, Geophys. Prospect., 52, 379-398.

Doetsch, J., Ingeman-Nielsen, T., Christiansen, A.V., Fiandaca, G., Auken, E. \& Elberling, B.(2015) Direct current (DC) resistivity and induced polarization (IP) monitoring of active layer dynamics at high temporal resolution, Cold Reg. Sci. Technol., 119, 16-28.

Dobinski, W., 2011. Permafrost, Earth Sci. Rev., 108, 158-169.

Duvillard, P.A., Revil, A., Qi, Y., Soueid Ahmed, A., Coperey, A. \& Ravanel, L., 2018. Three-dimensional electrical conductivity and induced polarization tomography of a rock glacier, J. geophys. Res., 123, doi:10.1029/2018JB015965.

Duvillard, P.-A., Ravanel, L., Marcer, M. \& Schoeneich, P., 2019. Recent evolution of damage to infrastructure on permafrost in the French Alps, Reg. Environ. Change, 19, 1281-1293.

Fortier, R., LeBlanc, A.-M., Allard, M., Buteau, S. \& Calmels, F., 2008. Internal structure and conditions of permafrost mounds at Umiujaq in Nunavik, Canada, inferred from field investigation and electrical resistivity tomography, Can. J. Earth Sci. 45, 367-387.

Grimm, R.E. \& Stillman, D.E., 2015. Field test of detection and characterisation of subsurface ice using broadband spectral-induced polarisation. Permafrost Periglac. Process., 26, 28-38.

Gruber, S. \& Haeberli, W., 2007. Permafrost in steep bedrock slopes and its temperature-related destabilization following climate change, J. geophys. Res. 112, doi:10.1029/2006JF000547.

Gruber, S., Hoelzle, M. \& Haeberli, W., 2004. Rock-wall temperatures in the Alps: modelling their topographic distribution and regional differences, Permafrost Periglac. Process., 15, 299-307.

Haeberli, W. \& Beniston, M., 1998. Climate change and its impacts on glaciers and permafrost in the Alps, Ambio, 27, 258-265.

Haeberli, W. et al., 2010. Mountain permafrost: development and challenges of a young research field, J. Glaciol., 56, 1043-1058.

Hasler, A., Gruber, S. \& Haeberli, W., 2011. Temperature variability and offset in steep alpine rock and ice faces, The Cryosphere, 5, 977-988.

Hauck, C., 2002. Frozen ground monitoring using DC resistivity tomography, Geophys. Res. Lett., 29, 12-1-12-4.

Hauck, C., Vonder Mühll, D. \& Maurer, H., 2003. Using DC resistivity tomography to detect and characterize mountain permafrost, Geophys. Prospect., 51, 273-284.

Hauck, C., Bottcher, M. \& Maurer, H., 2011. A new model for estimating subsurface ice content based on combined electrical and seismic data sets, Cryosphere 5, 453-468.

Herring, T., Cey, E. \& Pidlisecky, A., 2019. Electrical resistivity of a partially saturated porous medium at subzero temperatures, Vadose Zone J., 18, 111190019.
Hipp, T., Etzelmüller, B. \& Westermann, S., 2014. Permafrost in Alpine Rock Faces from Jotunheimen and Hurrungane, Southern Norway, Permafrost and Periglacial Processes, 25, 1-13.

Kemna, A. et al., 2012. An overview of the spectral induced polarization method for near-surface applications, Near Surf. Geophys., 10, 453-468.

Keuschnig, M., Krautblatter, M., Hartmeyer, I., Fuss, C. \& Schrott, L., 2017. Automated electrical resistivity tomography testing for early warning in unstable permafrost rock walls around Alpine infrastructure, Permafrost Periglac. Process., 28, 158-171.

Kneisel, C., 2006. Assessment of subsurface lithology in mountain environments using 2D resistivity imaging, Geomorphology, 80, 32-44.

Kneisel, C., Hauck, C., Fortier, R. \& Moorman, B., 2008. Advances in geophysical methods for permafrost investigations. Permafrost Periglac. Process., 19, 157-178.

Krautblatter, M. \& Hauck, C., 2007. Electrical resistivity tomography monitoring of permafrost in solid rock walls, J. geophys. Res., 112, doi:10.1029/2006JF000546.

Krautblatter, M., Verleysdonk, S., Flores-Orozco, A. \& Kemna, A., 2010. Temperature-calibrated imaging of seasonal changes in permafrost rock walls by quantitative electrical resistivity tomography (Zugspitze, German/Austrian Alps), J. geophys. Res., 115, doi:10.1029/2008JF001209.

Krautblatter, M., Huggel, C., Deline, P. \& Hasler, A., 2012. Research perspectives on unstable high-alpine bedrock permafrost: Measurement, modelling and process understanding, Permafrost Periglac. Process., 23, $80-88$.

Krautblatter, M., Funk, D. \& Günzel, F.K., 2013. Why permafrost rocks become unstable: a rock-ice-mechanical model in time and space. Earth Surf. Process. Landforms, 38, 876-887.

Kurylyk, B.L. \& Watanabe, K., 2013. The mathematical representation of freezing and thawing processes in variably-saturated, non-deformable soils. Adv. Water Res., 60, 160-177.

Labrecque, D. \& Daily, W., 2008, Assessment of measurement errors for galvanic-resistivity electrodes of different composition, Geophysics 73(2), doi:10.1190/1.2823457.

Legay, A., Magnin, F. \& Ravanel, L., submitted. Rock temperature prior to failure: analysis of 209 rockfall events in the Mont Blanc massif (Western European Alps), Permafrost Periglac. Process.

Leroy, P., Li, S., Jougnot, D., Revil, A. \& Wu, Y., 2017. Modeling the evolution of spectral induced polarization during calcite precipitation on glass beads, Geophys. J. Int., 209(1), 123-140.

Loke, M.H. \& Barker, R.D., 1996. Rapid least-squares inversion of apparent resistivity pseudosections by a quasi-Newton method, Geophys. Prospect., 44, 131-152.

Magnin, F., Deline, P., Ravanel, L., Noetzli, J. \& Pogliotti, P., 2015a. Thermal characteristics of permafrost in the steep alpine rock walls of the Aiguille du Midi (Mont Blanc Massif, 3842 m a.s.1), Cryosphere, 9, 109-121.

Magnin, F., Krautblatter, M., Deline, P., Ravanel, L., Malet, E. \& Bevington, A., 2015b. Determination of warm, sensitive permafrost areas in near-vertical rockwalls and evaluation of distributed models by electrical resistivity tomography, J. geophys. Res., 120, 745-762.

Magnin, F., Brenning, A., Bodin, X., Deline, P. \& Ravanel, L., 2015c. Modélisation statistique de la distribution du permafrost de paroi: application au massif du Mont Blanc, Géomorpholog. Relief Process. Environ., 21, 145-162.

Magnin, F., Josnin, J.-Y., Ravanel, L., Pergaud, J., Pohl, B. \& Deline, P., 2017. Modelling rock wall permafrost degradation in the Mont Blanc massif from the LIA to the end of the 21 st century, Cryosphere, 11, $1813-1834$

Magnin, F., Etzelmüller, B., Westermann, S., Isaksen, K., Hilger, P. \& Hermanns, R.L., 2019. Permafrost distribution in steep rock slopes in Norway: measurements, statistical modelling and implications for geomorphological processes, Earth Surf. Dynam., 7, 1019-1040.

Maurer, H. \& Hauck, C., 2007. Geophysical imaging of alpine rock glaciers. J. Glaciol., 53, 110-120.

Mollaret, C., Hilbich, C., Pellet, C., Flores-Orozco, A., Delaloye, R. \& Hauck, C., 2019. Mountain permafrost degradation documented through a network of permanent electrical resistivity tomography sites, Cryosphere, 13, 2557-2578. 
Mollaret, C., Wagner, F.M., Hilbich, C., Scapozza, C. \& Hauck, C., 2020. Petrophysical joint inversion applied to alpine permafrost field sites to image subsurface ice, water, air, and rock contents. Front. Earth Sci., 8. doi:10.3389/feart.2020.00085.

Mudler, J., Hördt, A., Przyklenk, A., Fiandaca, G., Maurya, P.K. \& Hauck, C., 2019. Two-dimensional inversion of wideband spectral data from the capacitively coupled resistivity method-first applications in periglacial environments. Cryosphere, 13, 2439-2456.

Noetzli, J., Gruber, S., Kohl, T., Salzmann, N. \& Haeberli, W., 2007. Three-dimensional distribution and evolution of permafrost temperatures in idealized high-mountain topography, J. geophys. Res., 112(F2), doi:10.1029/2006JF000545.

PERMOS 2019. Permafrost in Switzerland 2014/2015 to 2017/2018. Noetzli, J., Pellet, C. \& Staub, B.(eds.), Glaciological Report (Permafrost) No. 16-19 of the Cryospheric Commission of the Swiss Academy of Sciences, 104pp, doi:10.13093/permos-rep-2019-16-1

Pellet, C., Hilbish, C.,Marmy \& Hauck, C., 2016. Soil moisture data for the validation of permafrost models using direct and indirect measurements approaches at three Alpine Site. Front. Earth Sci., 3, 91, doi: 10.3389/feart.2015.00091.

Ravanel, L. \& Deline, P., 2011. Climate influence on rockfalls in highAlpine steep rockwalls: the north side of the Aiguilles de Chamonix (Mont Blanc massif) since the end of the 'Little Ice Age', Holocene, 21, 357-365.

Ravanel, L., Deline, P., Lambiel, C. \& Vincent, C., 2013. Instability of a high alpine rock ridge: the lower arête des cosmiques, mont blanc massif, france, Geogr. Ann. Ser. Phys. Geogr., 95, 51-66.

Ravanel, L., Magnin, F. \& Deline, P., 2017. Impacts of the 2003 and 2015 summer heatwaves on permafrost-affected rock-walls in the Mont Blanc massif, Sci. Total Environ., 609, 132-143.

Revil, A. et al., 2008. Inner structure of La Fossa di Vulcano (Vulcano Island, southern Tyrrhenian Sea, Italy) revealed by high resolution electric resistivity tomography coupled with self-potential, temperature, and soil $\mathrm{CO}_{2}$ diffuse degassing measurements, J. geophys. Res., 113, B07207, doi:10.1029/2007JB005394.

Revil, A., Florsch, N. \& Mao, D., 2015a. Induced polarization response of porous media with metallic particles - Part 1: a theory for disseminated semiconductors, Geophysics, 80(5), D525-D538.

Revil, A., Abdel Aal, G.Z., Atekwana, E.A., Mao, D. \& Florsch, N., 2015 b. Induced polarization response of porous media with metallic particles - Part 2. Comparison with a broad database of experimental data, Geophysics, 80(5), D539-D552.

Revil, A. et al., 2019a. Induced polarization response of porous media with metallic particles - Part 9. Influence of permafrost, Geophysics, 84(5), A43-W32.

Revil, A., Qi, Y., Ghorbani, A., Coperey, A., Soueid Ahmed, A., Finizola, A. \& Ricci, T., 2019b. Induced polarization of volcanic rocks. 3. Imaging clay cap properties in geothermal fields, Geophys. J. Int., 218(2), 1398-1427.

Revil, A., Ghorbani, A., Gailler, L.S., Gresse, M., Panwar, N. \& Sharma, R., 2018. Electrical conductivity and induced polarization investigations at Kilauea volcano, Hawai' i, J. Volc. Geotherm. Res., 368, 31-50.

Revil, A., 2013. Effective conductivity and permittivity of unsaturated porous materials in the frequency range $1 \mathrm{mHz}-1 \mathrm{GHz}$, Water Resour. Res., 49, 306-327.

Revil, A., 2012. Spectral induced polarization of shaly sands: influence of the electrical double layer, Water Resour. Res., 48, doi: 10.1029/2011WR011260.

Scott, W., Sellmann, P. \& Hunter, J., 1990. Geophysics in the Study of Permafrost. in Geotechnical and Environmental Geophysics Investigations in Geophysics, Vol. 1-0, 355-384, Society of Exploration Geophysicists, doi:10.1190/1.9781560802785.ch13.

Seigel, H.O., 1959. Mathematical formulation and type curves for induced polarization, Geophysics, 24, 547-565.
Supper, R., Ottowitz, D., Jochum, B., Römer, A., Pfeiler, S., Gruber, S., Keuschnig, M. \& Ita, A., 2014. Geoelectrical monitoring of frozen ground and permafrost in alpine areas: field studies and considerations towards an improved measuring technology, Surf. Geophys. 12, doi:10.3997/18730604.2013057.

Timur, A., 1968. Velocity of compressional waves in porous media at permafrost temperatures, Geophysics, 33, 584-595.

Wagner, F.M., Mollaret, C., Günther, T., Kemna, A. \& Hauck, C., 2019. Quantitative imaging of water, ice and air in permafrost systems through petrophysical joint inversion of seismic refraction and electrical resistivity data. Geophys. J. Int., 219, 1866-1875.

Weller, A., Slater, L. \& Nordsiek, S., 2013. On the relationship between induced polarization and surface conductivity: Implications for petrophysical interpretation of electrical measurements, Geophysics, 78, D315D325.

Westermann, S., Schuler, T.V., Gisnås, K. \& Etzelmüller, B., 2013. Transient thermal modeling of permafrost conditions in Southern Norway, Cryosphere, 7(2), 719-739.

\section{APPENDIX A. CONDUCTIVITY IN FREEZING CONDITIONS}

Our goal here is to connect the models developed by Duvillard et al. (2018) and Coperey et al. (2019b) to eq. (3) of the main text in freezing conditions. The assumptions we use here are the following (1) the mobility of the ions in the pore water and in the electrical double layer obey the same linear law with temperature below and above the freezing temperature (Coperey et al. 2019b), (2) the porous material is water saturated above the freezing temperature, (3) the cementation exponent and the saturation exponent are roughly the same (see Revil 2013, their fig. 18) and (4) the salt is entirely segregated in the liquid pore water. The conductivity at a water content $\theta$ is (Revil 2013):

$\sigma \approx \theta^{m} \sigma_{w}+\theta^{m-1} \rho_{g} B$ CEC,

where the various parameters are introduced in the main text. Assumption (4) implies that the conductivity of the pore water should scale as the inverse of the pore water $s_{w}$ leading to (see Coperey et al. 2019b, their eq. 12)

$\sigma(T) \approx \theta(T)^{m}\left[\phi \sigma_{w}(T)+\rho_{g} B(T) \mathrm{CEC}\right]$.

The temperature dependence of the ionic mobilities entering the conductivity of the pore water and the mobility $B$ are the same and related to the dependence of the viscosity of the pore water with temperature. $\left(\sim 1+\alpha_{T}\left(T-T_{0}\right)\right.$ where $T_{0}$ denotes a reference temperature, e.g. $\left.25^{\circ} \mathrm{C}\right)$. This leads to:

$\sigma(T) \approx \theta(T)^{m}\left[\phi \sigma_{w}\left(T_{0}\right)+\rho_{g} B\left(T_{0}\right) \mathrm{CEC}\right]\left[1+\alpha_{T}\left(T-T_{0}\right)\right]$.

We need now to simplify the writing of eq. (A3). We first write the conductivity at the reference temperature $T_{0}$ assuming that the porous material is fully water saturated at this temperature (in this case $\theta=\theta_{S}=\phi$ where $\theta_{S}$ is the water content at saturation and $\phi$ the connected porosity), we obtain

$\sigma\left(T_{0}\right) \approx \phi^{2} \sigma_{w}\left(T_{0}\right)+\phi \rho_{g} B\left(T_{0}\right)$ CEC.

which is strictly valid for $m=2$ and a very good approximation for other values of $m$ when inserted in eq. (A3). Combining eqs (A3) and (A4) yields eq. (3) of the main text. The same derivation can be applied to eq. (6) with $M_{n}\left(T_{0}\right) \approx \phi \rho_{g} \lambda\left(T_{0}\right) \mathrm{CEC}$. 